\title{
DECOMPOSING THE LUENBERGER-HICKS-MOORSTEEN TOTAL FACTOR PRODUCTIVITY INDICATOR: AN APPLICATION TO U.S. AGRICULTURE
}

\author{
FREDERIC ANG AND PIETER JAN KERSTENS
}

\begin{abstract}
This paper introduces a decomposition of the additively complete Luenberger-Hicks-Moorsteen Total Factor Productivity indicator into the usual components: technical change, technical inefficiency change and scale inefficiency change. Our approach is general in that it does not require differentiability or convexity of the production technology. Using a nonparametric framework, the empirical application focuses on the agricultural sector at the state-level in the U.S. over the period $1960-2004$. The results show that Luenberger-Hicks-Moorsteen productivity increased substantially in the considered period. This productivity growth is due to output growth rather than input decline, although the extent depends on the convexity assumption of the technology. Technical change is the main driver, while the role of technical inefficiency change and scale inefficiency change also depends on the convexity assumption of the technology.
\end{abstract}

Keywords Data Envelopment Analysis, Luenberger-Hicks-Moorsteen total factor productivity indicator, decomposition, non-convex technology, additive completeness

JEL codes C43, D24, Q10

Department of Economics, Swedish University of Agricultural Sciences, Box 7013, SE-750 07 Uppsala, Sweden

Center for Economic Studies, Ku Leuven, E. Sabbelaan 53, B-8500 Kortrijk, BELGIUM, TEL: +3216330765

The authors gratefully acknowledge two anonymous referees for their valuable comments and suggestions. The authors also thank Laurens Cherchye for helpful comments and suggestions. Email pieterjan.kerstens@kuleuven.be for correspondence. Both authors have contributed equally to this paper. Any remaining errors are the responsibility of the authors. 


\section{Introduction}

Assessing the drivers of productivity growth is important for business and economic policy. Their identification allows monitoring of industries and can guide policymakers in their decisions. Hence, an abundant literature has sought to decompose various measures of productivity growth into components of technical change, efficiency change and scale efficiency change. ${ }^{1}$ The literature has largely focused on ratio-based productivity "indexes". Yet, O'Donnell (2012a) recently shows that not all such decomposable indexes are "multiplicatively complete" (i.e. consisting of a ratio of an output aggregator to an input aggregator), while all multiplicatively complete indexes are decomposable in this way. He demonstrates that the class of multiplicatively complete productivity indexes includes Laspeyres, Paasche, Fischer, Törnqvist and Bjurek (1996)'s Hicks-Moorsteen indexes, but does not include the popular Malmquist index of Caves et al. (1982).

Ratio-based productivity indexes are undefined when one or more of the variables are equal or close to zero (Balk et al., 2003). Difference-based productivity "indicators" do not suffer from this problem and are thus particularly useful in regulatory contexts.

Difference-based indicators were developed to measure Total Factor Productivity (TFP) growth based on Luenberger (1992)'s shortage function. This directional distance function, introduced by Chambers et al. (1996) in a production context, extends the Shephard input and output distance functions by allowing for simultaneous contraction of inputs and expansion of outputs. Chambers (2002) introduced a general difference-based Luenberger productivity indicator which can be decomposed in a technical change and efficiency change component (Chambers et al., 1996). ${ }^{2}$ Since its introduction, it has frequently been applied in empirical applications (e.g. Nakano and Managi (2008)) and additional decompositions of its technical change component (e.g. Briec and Peypoch (2007)) and efficiency change component (e.g. Epure et al. (2011)) have been proposed in the literature. However, the Luenberger productivity indicator is not "additively complete" (i.e. consisting of a difference between an output aggregator and an input aggregator) and thus cannot be disentangled into components of output growth and input growth.

Briec and Kerstens (2004) introduced the Luenberger-Hicks-Moorsteen (LHM) TFP indicator, which is a difference-based, additively complete alternative to the

\footnotetext{
${ }^{1}$ See Färe et al. (1998) and Grosskopf (2003) for historical overviews.

${ }^{2}$ The "economic" approach to productivity measurement requires price information and if in addition (i) some assumptions can be made about firm behavior and (ii) the technology is approximated by a known flexible functional form up to the second order, then one can use a "superlative" index as advocated by Diewert (1976). Chambers (2002) showed that the BennetBowley indicators are exact and superlative approximations of the Luenberger productivity indicator under (i) profit-maximizing behavior and (ii) a quadratic technology directional distance function. A corresponding superlative indicator for the LHM TFP indicator is currently not known.
} 
ratio-based, multiplicatively complete Hicks-Moorsteen index. ${ }^{3}$ Notwithstanding the attractive properties of the LHM TFP indicator, only few empirical studies can be found in the literature (e.g. Barros et al. (2008) and Managi (2010)). One possible reason for the limited number of applications is the fact that a full decomposition into components of technical change, technical inefficiency change and scale inefficiency change has hitherto not been developed. A first effort was made by Managi (2010) who decomposed the LHM TFP indicator into components of technical change and (in)efficiency change. However, this decomposition lacks a scale inefficiency change component and does not correctly capture technical change and technical inefficiency change (see Appendix A). No full decomposition of a difference-based TFP indicator being additively complete is thus presently known in the literature.

The current paper contributes to the existing literature by introducing a decomposition of the additively complete LHM TFP indicator into components of technical change, technical inefficiency change and scale inefficiency change. Our decomposition is general in that it does not require convexity or differentiability of the technology set. It is similar to Diewert and Fox $(2014,2017)$ 's decomposition of the ratio-based Hicks-Moorsteen TFP index.

Using a nonparametric framework, we illustrate the decomposition with an empirical application to state-level data of the U.S. agricultural sector over the period $1960-2004$. Since our decomposition is suitable for non-convex as well as convex technologies, we demonstrate its flexibility by using the Free Disposal Hull as well as Data Envelopment Analysis. To the best of our knowledge, no other studies using the same dataset have investigated the issue of potential non-convexities. However, we believe that such an investigation is particularly relevant in the context of the agricultural sector. Inputs such as capital equipment are nondivisible, potentially leading to non-convexities.

This paper is structured as follows. The next section describes Luenberger's directional distance function and the LHM TFP indicator. We then introduce our complete decomposition and apply this to state-level data of the U.S. agricultural sector over the period $1960-2004$. The final section concludes.

\section{The Luenberger-Hicks-Moorsteen TFP indicator}

Let $\mathbf{x}_{t} \in \mathbb{R}_{+}^{n}$ be the nonnegative inputs that are used to produce nonnegative outputs $\mathbf{y}_{t} \in \mathbb{R}_{+}^{m}$. We define the technology set in the usual way:

$$
\mathcal{Y}_{t}=\left\{\left(\mathbf{x}_{t}, \mathbf{y}_{t}\right) \in \mathbb{R}_{+}^{n+m} \mid \mathbf{x}_{t} \text { can produce } \mathbf{y}_{t}\right\}
$$

Furthermore, we make the following minimal assumptions on the technology set (Chambers, 2002):

\footnotetext{
${ }^{3}$ See Briec et al. (2012) for exact relations between the Luenberger-Hicks-Moorsteen TFP indicator and the Hicks-Moorsteen TFP index.
} 
Axiom 1 (Closedness). $\mathcal{Y}_{t}$ is closed.

Axiom 2 (Free disposability of inputs and outputs). if $\left(\mathbf{x}_{t}^{\prime},-\mathbf{y}_{t}^{\prime}\right) \geq\left(\mathbf{x}_{t},-\mathbf{y}_{t}\right)$ then $\left(\mathrm{x}_{t}, \mathrm{y}_{t}\right) \in \mathcal{Y}_{t} \Rightarrow\left(\mathrm{x}_{t}^{\prime}, \mathrm{x}_{t}^{\prime}\right) \in \mathcal{Y}_{t}$

Axiom 3 (Inaction). Inaction is possible: $\left(\mathbf{0}^{n}, \mathbf{0}^{m}\right) \in \mathcal{Y}_{t}$.

Convexity of the technology set is thus not a necessary condition for our decomposition. ${ }^{4}$ We illustrate this in our empirical application.

Luenberger's directional distance function is a measure of technical inefficiency as it simultaneously contracts inputs and expands outputs. The directional distance function proposed by Chambers et al. (1996) is:

$$
D_{t}\left(\mathbf{x}_{t}, \mathbf{y}_{t} ; \mathbf{g}_{t}\right)=\sup \left\{\beta \in \mathbb{R}:\left(\mathbf{x}_{t}-\beta \mathbf{g}_{t}^{i}, \mathbf{y}_{t}+\beta \mathbf{g}_{t}^{o}\right) \in \mathcal{Y}_{t}\right\},
$$

if $\left(\mathbf{x}_{t}-\beta \mathbf{g}_{t}^{i}, \mathbf{y}_{t}+\beta \mathbf{g}_{t}^{o}\right) \in \mathcal{Y}_{t}$ for some $\beta$ and $D_{t}\left(\mathbf{x}_{t}, \mathbf{y}_{t} ; \mathbf{g}_{t}\right)=-\infty$ otherwise. Here, $\mathbf{g}_{t}=\left(\mathbf{g}_{t}^{i}, \mathbf{g}_{t}^{o}\right)$ represents the direction vector. The directional distance function is a special case of Luenberger (1992)'s shortage function.

We denote the time-related directional distance function for $(a, b) \in\{t, t+1\} \times$ $\{t, t+1\}$ :

$$
D_{b}\left(\mathbf{x}_{a}, \mathbf{y}_{a} ; \mathbf{g}_{a}\right)=\sup \left\{\beta \in \mathbb{R}:\left(\mathbf{x}_{a}-\beta \mathbf{g}_{a}^{i}, \mathbf{y}_{a}+\beta \mathbf{g}_{a}^{o}\right) \in \mathcal{Y}_{b}\right\} .
$$

Next, we turn to the Luenberger-Hicks-Moorsteen (LHM) TFP indicator proposed by Briec and Kerstens (2004). This can be seen as the difference-based equivalent of the ratio-based Hicks-Moorsteen (HM) TFP index. They define the LHM TFP indicator with base period $t$ as the difference between a Luenberger output quantity indicator and a Luenberger input quantity indicator:

$$
\begin{aligned}
& L H M_{t}\left(\mathbf{x}_{t+1}, \mathbf{y}_{t+1}, \mathbf{x}_{t}, \mathbf{y}_{t} ; \mathbf{g}_{t}, \mathbf{g}_{t+1}\right) \\
& =\left[D_{t}\left(\mathbf{x}_{t}, \mathbf{y}_{t} ;\left(0, \mathbf{g}_{t}^{o}\right)\right)-D_{t}\left(\mathbf{x}_{t}, \mathbf{y}_{t+1} ;\left(0, \mathbf{g}_{t+1}^{o}\right)\right)\right] \\
& -\left[D_{t}\left(\mathbf{x}_{t+1}, \mathbf{y}_{t} ;\left(\mathbf{g}_{t+1}^{i}, 0\right)\right)-D_{t}\left(\mathbf{x}_{t}, \mathbf{y}_{t} ;\left(\mathbf{g}_{t}^{i}, 0\right)\right)\right] \\
& \equiv L O_{t}\left(\mathbf{x}_{t}, \mathbf{y}_{t}, \mathbf{y}_{t+1} ; \mathbf{g}_{t}^{o}, \mathbf{g}_{t+1}^{o}\right)-L I_{t}\left(\mathbf{x}_{t}, \mathbf{x}_{t+1}, \mathbf{y}_{t} ; \mathbf{g}_{t}^{i}, \mathbf{g}_{t+1}^{i}\right) .
\end{aligned}
$$

Similarly, a base period $t+1$ LHM TFP indicator is defined as:

$$
\begin{aligned}
& L H M_{t+1}\left(\mathbf{x}_{t+1}, \mathbf{y}_{t+1}, \mathbf{x}_{t}, \mathbf{y}_{t} ; \mathbf{g}_{t}, \mathbf{g}_{t+1}\right) \\
& =\left[D_{t+1}\left(\mathbf{x}_{t+1}, \mathbf{y}_{t} ;\left(0, \mathbf{g}_{t}^{o}\right)\right)-D_{t+1}\left(\mathbf{x}_{t+1}, \mathbf{y}_{t+1} ;\left(0, \mathbf{g}_{t+1}^{o}\right)\right)\right] \\
& -\left[D_{t+1}\left(\mathbf{x}_{t+1}, \mathbf{y}_{t+1} ;\left(\mathbf{g}_{t+1}^{i}, 0\right)\right)-D_{t+1}\left(\mathbf{x}_{t}, \mathbf{y}_{t+1} ;\left(\mathbf{g}_{t}^{i}, 0\right)\right)\right] \\
& \equiv L O_{t+1}\left(\mathbf{x}_{t+1}, \mathbf{y}_{t+1}, \mathbf{y}_{t} ; \mathbf{g}_{t}^{o}, \mathbf{g}_{t+1}^{o}\right)-L I_{t+1}\left(\mathbf{x}_{t}, \mathbf{x}_{t+1}, \mathbf{y}_{t+1} ; \mathbf{g}_{t}^{i}, \mathbf{g}_{t+1}^{i}\right) .
\end{aligned}
$$

\footnotetext{
${ }^{4}$ In fact, the LHM TFP indicator and our decomposition are applicable to a wider range of non-convex models that satisfy the above axioms and for which the directional distance function can be defined. Examples of these non-convex models include the Constant-Elasticityof-Substitution-Constant-Elasticity-of-Transformation model of Färe et al. (1988), relaxed convexity model of Petersen (1990) and Bogetoft (1996), selective convexity model of Podinovski (2005) and B-convexity model of Briec and Liang (2011).
} 
O’Donnell (2012a) (p.258, footnote 5) defines additive completeness as follows:

Definition 1 (Additive completeness). Formally, let TFPI $\left(x_{t}, q_{t}, x_{s}, q_{s}\right)$ denote an index number that compares TFP in period $s$ with TFP in period $t$ using period $s$ as a base. TFPI $\left(x_{t}, q_{t}, x_{s}, q_{s}\right)$ is additively complete if and only if it can be expressed in the form TFPI $\left(x_{t}, q_{t}, x_{s}, q_{s}\right)=Q\left(q_{t}\right)-Q\left(q_{s}\right)-X\left(x_{t}\right)+X\left(x_{s}\right)$ where $Q(\cdot)$ and $X(\cdot)$ are non-negative non-decreasing functions satisfying the translation property $Q(q+\lambda q)=Q(q)+\lambda$ and $X(x+\lambda x)=X(x)+\lambda$ for $\lambda>0$.

$L H M_{t}(\cdot)$ and $L H M_{t+1}(\cdot)$ are "additively complete" in O'Donnell's sense. This can be verified from their definitions above where the directional distance function, along with its corresponding direction vector, serves as the output (using $\left(0, \mathbf{g}_{s}^{o}\right)$ ) and input (using $\left.\left(\mathbf{g}_{s}^{i}, 0\right)\right)$ aggregator functions. ${ }^{5}$

Finally, one takes an arithmetic average of $L H M_{t}$ and $L H M_{t+1}$ to avoid an arbitrary choice of base periods: ${ }^{6}$

$$
L H M_{t, t+1}\left(\mathbf{x}_{t}, \mathbf{y}_{t}, \mathbf{x}_{t+1}, \mathbf{y}_{t+1} ; \mathbf{g}_{t}, \mathbf{g}_{t+1}\right)=\frac{1}{2}\left[L H M_{t}+L H M_{t+1}\right] .
$$

The HM TFP index is defined as the ratio of an output index to an input index. Similarly, we can show that the LHM TFP indicator equals the difference between an output indicator and an input indicator, which are themselves arithmetic averages of two output and two input indicators:

$$
\begin{aligned}
L H M_{t, t+1} & =\frac{1}{2}\left[L O_{t}+L O_{t+1}\right]-\frac{1}{2}\left[L I_{t}+L I_{t+1}\right] \\
& \equiv L O_{t, t+1}-L I_{t, t+1} .
\end{aligned}
$$

\footnotetext{
5Luenberger (1992)'s shortage function differs from Chambers (2002)' Luenberger productivity indicator. The shortage function satisfies the translation property. It is an aggregator function that can be used to compute components of an additively complete indicator (such as the LHM TFP indicator), but is not additively complete. Chambers (2002) defines the Luenberger productivity indicator as follows:

$$
\begin{aligned}
L_{t, t+1} & \left(\mathbf{x}_{t}, \mathbf{y}_{t}, \mathbf{x}_{t+1}, \mathbf{y}_{t+1} ; \mathbf{g}_{t}, \mathbf{g}_{t+1}\right) \\
& =\frac{1}{2}\left[\left(D_{t}\left(\mathbf{x}_{t}, \mathbf{y}_{t} ; \mathbf{g}_{t}\right)-D_{t}\left(\mathbf{x}_{t+1}, \mathbf{y}_{t+1} ; \mathbf{g}_{t+1}\right)\right)\right. \\
& \left.+\left(D_{t+1}\left(\mathbf{x}_{t}, \mathbf{y}_{t} ; \mathbf{g}_{t}\right)-D_{t+1}\left(\mathbf{x}_{t+1}, \mathbf{y}_{t+1} ; \mathbf{g}_{t+1}\right)\right)\right],
\end{aligned}
$$

All directional vectors are determined in the input direction as well as the output direction, i.e. $\mathbf{g}_{a}=\left(\mathbf{g}_{a}^{i}, \mathbf{g}_{a}^{o}\right)>0$. This prevents us from disentangling the indicator into separate output and input aggregator functions.

${ }^{6}$ This average can be harder to interpret in regulatory and managerial contexts in which a clearer target is required. This can easily be accounted for by a different choice of weights for both periods: i.e. we can define $L H M_{t, t+1}=\zeta L H M_{t}+(1-\zeta) L H M_{t+1}$ with weights $\zeta \in[0,1]$. One can then for example set $\zeta=0$ or $\zeta=1$. These weights trickle down in the technical change and scale inefficiency change components of our decomposition in a straightforward way.
} 


\section{Decomposition of the Luenberger-Hicks-Moorsteen indicAtor}

This section introduces our LHM decomposition along with illustrative figures in the one input - one output dimension to provide the intuition. We show an example with a non-convex technology (i.e. Free Disposal Hull), as convexity is not a necessary assumption for our decomposition. Note, however, that one can also use our approach for a convex technology.

In line with the decomposition of the HM TFP index, the LHM TFP indicator can be decomposed using the output direction or input direction. ${ }^{7}$ We focus on the decomposition using the output direction, but provide a similar decomposition using the input direction in Appendix B. Our LHM decomposition is a specific case (analogous to the multiplicatively complete case discussed in Section 3.7 of O'Donnell (2012a)) of an additively complete indicator that uses the directional distance function as the aggregator function for both inputs and outputs. Hence, in our case the mix efficiency change components are all 0 and our decomposition consists of three components:

$$
L H M_{t, t+1}=\Delta T_{t, t+1}^{o}+\Delta T E I_{t, t+1}^{o}+\Delta S E C_{t, t+1}^{o},
$$

representing technical change, technical inefficiency change and scale inefficiency change respectively. ${ }^{8}$ Given the close relation to the HM TFP index, it is no surprise that our decomposition is similar to Diewert and Fox $(2014,2017)$ 's decomposition of the HM TFP index.

The technical change component is

$$
\begin{aligned}
\Delta T_{t, t+1}^{o} & =\frac{1}{2}\left\{\left[D_{t+1}\left(\mathbf{x}_{t}, \mathbf{y}_{t} ;\left(0, \mathbf{g}_{t}^{o}\right)\right)-D_{t}\left(\mathbf{x}_{t}, \mathbf{y}_{t} ;\left(0, \mathbf{g}_{t}^{o}\right)\right)\right]\right. \\
& \left.+\left[D_{t+1}\left(\mathbf{x}_{t+1}, \mathbf{y}_{t+1} ;\left(0, \mathbf{g}_{t+1}^{o}\right)\right)-D_{t}\left(\mathbf{x}_{t+1}, \mathbf{y}_{t+1} ;\left(0, \mathbf{g}_{t+1}^{o}\right)\right)\right]\right\} \\
& \equiv \frac{1}{2}\left\{\Delta T_{t}^{o}+\Delta T_{t+1}^{o}\right\} .
\end{aligned}
$$

Technical change $\Delta T_{t, t+1}^{o}$ is the arithmetic average of $\Delta T_{t}^{o}$ and $\Delta T_{t+1}^{o}$. Figure 1 depicts these technical change components. The arithmetic average is used to avoid an arbitrary choice of the observation under evaluation. Here, $\Delta T_{t}^{o}$ measures the difference in efficiency for observation $\left(\mathbf{x}_{t}, \mathbf{y}_{t}\right)$ evaluated against production frontier $t+1$ and $t$. An upward (downward) shift of the production frontier between $t$ and $t+1$, indicating technical progress (regress), results in a positive (negative)

\footnotetext{
${ }^{7}$ The technical change and technical inefficiency change components in particular are completely determined by this choice. The additive completeness property of the LHM TFP indicator can guide this decision by checking whether LHM TFP is mostly driven by $L O_{t, t+1}$ or $L I_{t, t+1}$. This contrasts with the Luenberger productivity indicator where both inputs and outputs contribute to its components.

${ }^{8}$ Managi (2010)'s decomposition lacks a scale inefficiency change component. We refer to Appendix A for a discussion.
} 
difference. $\Delta T_{t+1}^{o}$ is similar to $\Delta T_{t}^{o}$ but evaluated for observation $\left(\mathbf{x}_{t+1}, \mathbf{y}_{t+1}\right)$. Thus, technical change measures (local) shifts of the production frontier itself.

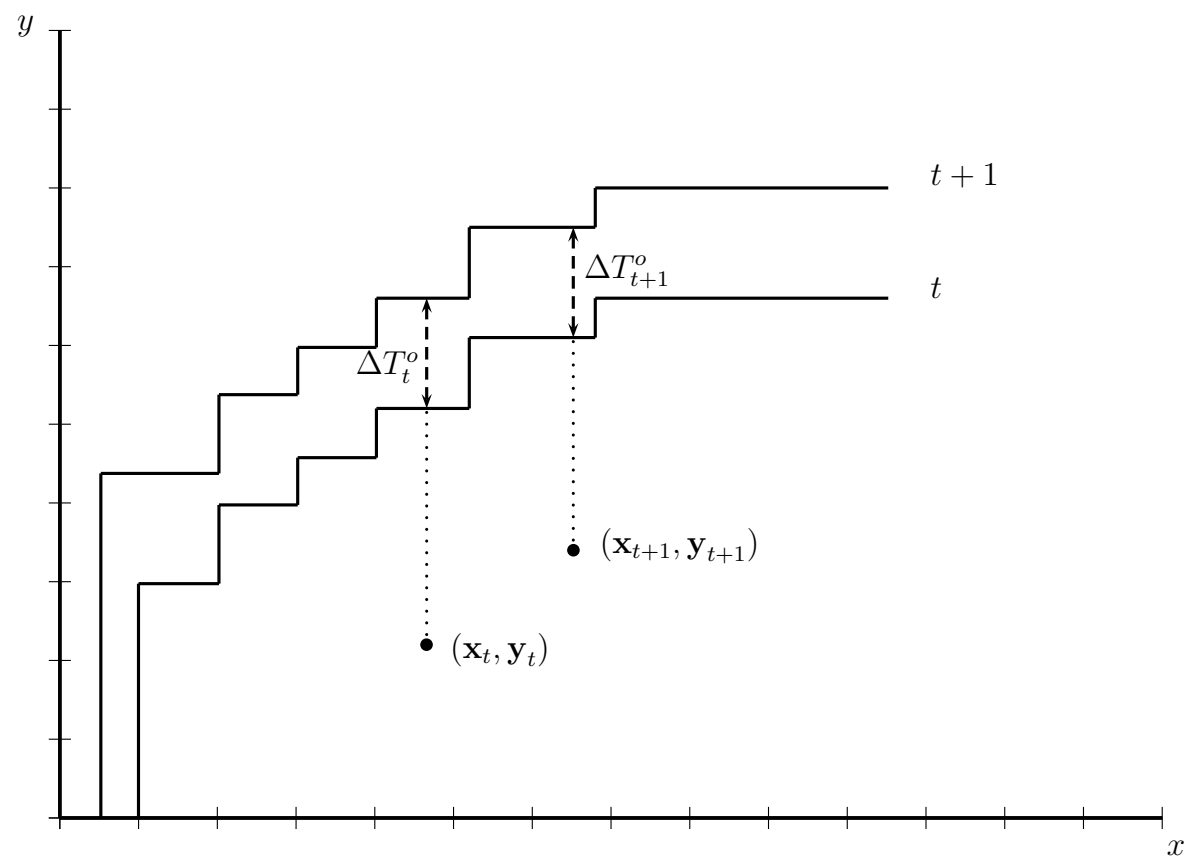

FiguRE 1. Technical change

The technical inefficiency change component is

$$
\Delta T E I_{t, t+1}^{o}=D_{t}\left(\mathbf{x}_{t}, \mathbf{y}_{t} ;\left(0, \mathbf{g}_{t}^{o}\right)\right)-D_{t+1}\left(\mathbf{x}_{t+1}, \mathbf{y}_{t+1} ;\left(0, \mathbf{g}_{t+1}^{o}\right)\right)
$$

and measures the change between period $t$ and period $t+1$ in the relative position to the production frontier. Positive (negative) values of $\Delta T E I_{t, t+1}^{o}$ indicate efficiency improvement (deterioration) over time: $\left(\mathbf{x}_{t+1}, \mathbf{y}_{t+1}\right)$ is located closer (farther) to the $t+1$ frontier than $\left(\mathbf{x}_{t}, \mathbf{y}_{t}\right)$ was to the $t$ frontier. In Figure 2 this means that $D_{t+1}\left(\mathbf{x}_{t+1}, \mathbf{y}_{t+1}\right)$ is smaller (larger) than $D_{t}\left(\mathbf{x}_{t}, \mathbf{y}_{t}\right)$. Note that $\Delta T E I^{o}$ only measures the evolution in technical efficiency of the observation under consideration without taking into account changes of the production frontier over time.

This technical inefficiency change component can be further decomposed in the same way as done by Epure et al. (2011) for the Luenberger indicator into "pure" inefficiency and, for example, congestion changes. 


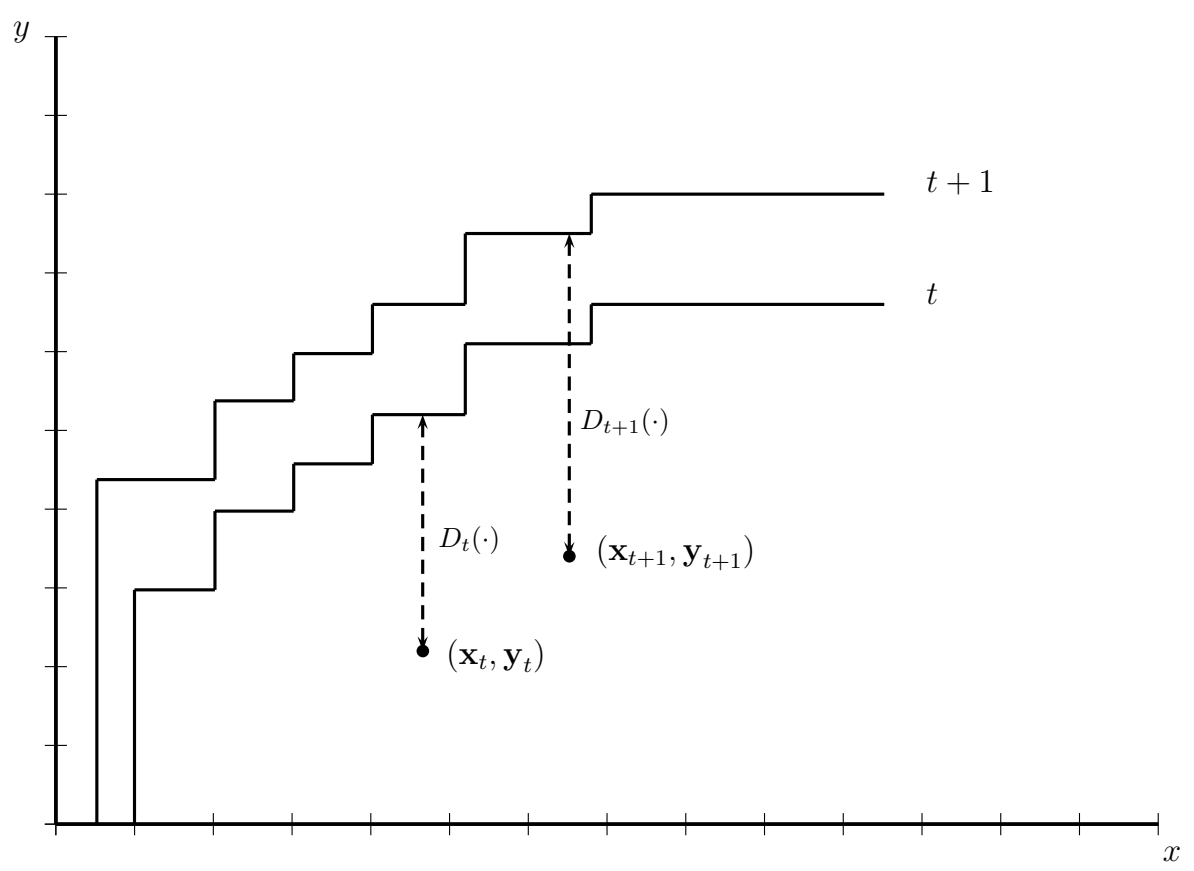

Figure 2. Technical inefficiency change

Finally, from the residual

(9)

$$
\begin{aligned}
L H M_{t, t+1}- & \Delta T_{t, t+1}^{o}-\Delta T E I_{t, t+1}^{o} \\
= & \frac{1}{2}\left\{\left[D_{t}\left(\mathbf{x}_{t+1}, \mathbf{y}_{t+1} ;\left(0, \mathbf{g}_{t+1}^{o}\right)\right)-D_{t}\left(\mathbf{x}_{t}, \mathbf{y}_{t+1} ;\left(0, \mathbf{g}_{t+1}^{o}\right)\right)\right]\right. \\
& \left.+\left[D_{t+1}\left(\mathbf{x}_{t+1}, \mathbf{y}_{t} ;\left(0, \mathbf{g}_{t}^{o}\right)\right)-D_{t+1}\left(\mathbf{x}_{t}, \mathbf{y}_{t} ;\left(0, \mathbf{g}_{t}^{o}\right)\right)\right]\right\} \\
- & \frac{1}{2}\left\{\left[D_{t}\left(\mathbf{x}_{t+1}, \mathbf{y}_{t} ;\left(\mathbf{g}_{t+1}^{i}, 0\right)\right)-D_{t}\left(\mathbf{x}_{t}, \mathbf{y}_{t} ;\left(\mathbf{g}_{t}^{i}, 0\right)\right)\right]\right. \\
& \left.+\left[D_{t+1}\left(\mathbf{x}_{t+1}, \mathbf{y}_{t+1} ;\left(\mathbf{g}_{t+1}^{i}, 0\right)\right)-D_{t+1}\left(\mathbf{x}_{t}, \mathbf{y}_{t+1} ;\left(\mathbf{g}_{t}^{i}, 0\right)\right)\right]\right\}
\end{aligned}
$$

we can distill the scale inefficiency change component as follows. First, we define the projections of $\mathbf{y}_{t}$ and $\mathbf{y}_{t+1}$ on the production frontier at time $t$ using notation of Diewert and Fox (2017):

$$
\begin{aligned}
& \mathbf{y}_{t}^{*}=\mathbf{y}_{t}+D_{t}\left(\mathbf{x}_{t}, \mathbf{y}_{t} ;\left(0, \mathbf{g}_{t}^{o}\right)\right) \mathbf{g}_{t}^{o} \\
& \mathbf{y}_{t+1}^{* *}=\mathbf{y}_{t+1}+D_{t}\left(\mathbf{x}_{t+1}, \mathbf{y}_{t+1} ;\left(0, \mathbf{g}_{t+1}^{o}\right)\right) \mathbf{g}_{t+1}^{o}
\end{aligned}
$$

Similarly, we define the projections of $\mathbf{y}_{t}$ and $\mathbf{y}_{t+1}$ on the production frontier at time $t+1$ :

$$
\begin{aligned}
& \mathbf{y}_{t}^{* *}=\mathbf{y}_{t}+D_{t+1}\left(\mathbf{x}_{t}, \mathbf{y}_{t} ;\left(0, \mathbf{g}_{t}^{o}\right)\right) \mathbf{g}_{t}^{o} \\
& \mathbf{y}_{t+1}^{*}=\mathbf{y}_{t+1}+D_{t+1}\left(\mathbf{x}_{t+1}, \mathbf{y}_{t+1} ;\left(0, \mathbf{g}_{t+1}^{o}\right)\right) \mathbf{g}_{t+1}^{o}
\end{aligned}
$$


Then, respectively adding and subtracting $D_{t}\left(\mathbf{x}_{t}, \mathbf{y}_{t} ;\left(0, \mathbf{g}_{t}^{o}\right)\right)$ and $D_{t+1}\left(\mathbf{x}_{t+1}, \mathbf{y}_{t+1} ;\left(0, \mathbf{g}_{t+1}^{o}\right)\right)$ to and from (9), and using the translation property of the directional distance function and the definitions of the projections above, we find the scale inefficiency change component:

$$
\begin{aligned}
\Delta S E C_{t, t+1}^{o} & =\frac{1}{2}\left\{\left[D_{t}\left(\mathbf{x}_{t}, \mathbf{y}_{t}^{*} ;\left(0, \mathbf{g}_{t}^{o}\right)\right)-D_{t}\left(\mathbf{x}_{t}, \mathbf{y}_{t+1}^{* *} ;\left(0, \mathbf{g}_{t+1}^{o}\right)\right)\right]\right. \\
& -\left[D_{t}\left(\mathbf{x}_{t+1}, \mathbf{y}_{t} ;\left(\mathbf{g}_{t+1}^{i}, 0\right)\right)-D_{t}\left(\mathbf{x}_{t}, \mathbf{y}_{t} ;\left(\mathbf{g}_{t}^{i}, 0\right)\right)\right] \\
& +\left[D_{t+1}\left(\mathbf{x}_{t+1}, \mathbf{y}_{t}^{* *} ;\left(0, \mathbf{g}_{t}^{o}\right)\right)-D_{t+1}\left(\mathbf{x}_{t+1}, \mathbf{y}_{t+1}^{*} ;\left(0, \mathbf{g}_{t+1}^{o}\right)\right)\right] \\
& \left.-\left[D_{t+1}\left(\mathbf{x}_{t+1}, \mathbf{y}_{t+1} ;\left(\mathbf{g}_{t+1}^{i}, 0\right)\right)-D_{t+1}\left(\mathbf{x}_{t}, \mathbf{y}_{t+1} ;\left(\mathbf{g}_{t}^{i}, 0\right)\right)\right]\right\} \\
& \equiv \frac{1}{2}\left\{S O C_{t}^{o}-S I C_{t}^{o}+S O C_{t+1}^{o}-S I C_{t+1}^{o}\right\} \\
& \equiv \frac{1}{2}\left\{\Delta S E C_{t}^{o}+\Delta S E C_{t+1}^{o}\right\},
\end{aligned}
$$

which has the interpretation of measuring changes in "global" returns to scale in line with Diewert and Fox (2017). As a result, our scale inefficiency change component does not require differentiability or convexity of the production technology. Figure 3 illustrates the intuition behind (12). Again, the arithmetic average of $\triangle S E C_{t}^{o}$ and $\triangle S E C_{t+1}^{o}$ is used to avoid an arbitrary choice of base period for the technology. Both components have a similar interpretation as a finite difference approximation of the frontier's gradient. $\triangle S E C_{t}^{o}$ is a finite difference approximation of the frontier $t$ 's gradient and measures the change in inputs and outputs along the frontier when going from $\left(\mathbf{x}_{t}, \mathbf{y}_{t}\right)$ to $\left(\mathbf{x}_{t+1}, \mathbf{y}_{t+1}\right)$. The change in inputs and outputs is measured separately: the $S O C_{t}^{o}\left(S I C_{t}^{o}\right)$ subcomponent of $\triangle S E C_{t}^{o}$ keeps the inputs (outputs) constant while measuring the change in the level of outputs (inputs).

This "residual" approach of Diewert and Fox (2017) differs from the traditional "Constant-Returns-to-Scale-Variable-Returns-to-Scale" (CRS-VRS) approach of Färe et al. (1994) for the Malmquist index and Epure et al. (2011) for the Luenberger indicator. The CRS-VRS approach compares the VRS frontier to a (hypothetical) benchmark CRS frontier to detect changes in returns to scale over time. In contrast, the residual approach directly considers changes in the frontier's gradient over time to assess scale inefficiency change. Thus, the main difference is that the Färe et al. (1994) approach relies on two frontiers (VRS and CRS) to measure scale inefficiency change, while the residual approach of Diewert and Fox (2017) only uses one frontier (VRS in our case).

From a theoretical point of view, CRS is often not a realistic assumption whereby this hypothetical CRS frontier to measure changes in returns-to-scale is not appropriate. In contrast, the main strength of the residual approach is that we do not need to introduce a CRS component into the LHM TFP indicator to detect changes in returns-to-scale. If the technology exhibits CRS then this will be 


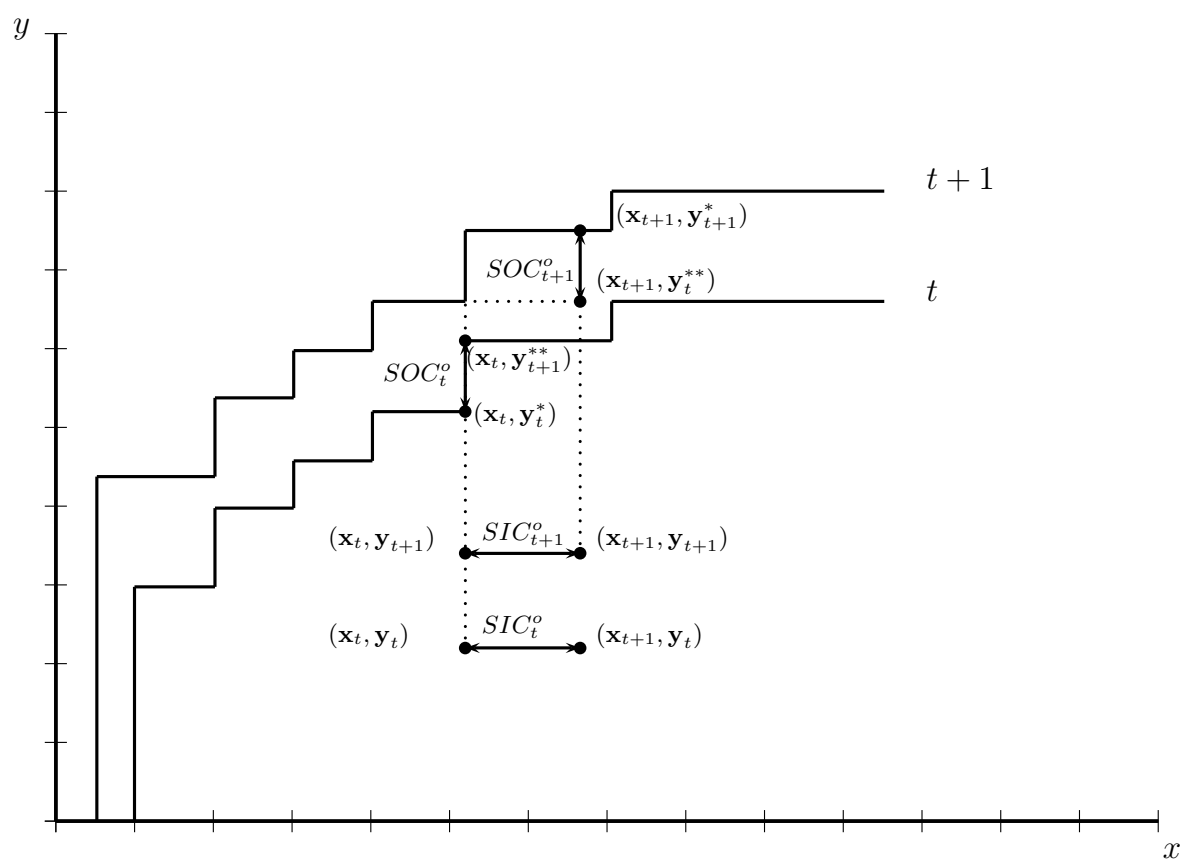

Figure 3. Scale inefficiency change

automatically reflected in zero values for the $\triangle S E C_{t, t+1}^{o}$ component even if we use a VRS approximation. Of course, depending on the application at hand and results of a preliminary test on returns-to-scale, the LHM TFP indicator and our decomposition can also be computed under other returns-to-scale assumptions. From a practical point of view, an obvious drawback to the "CRS-VRS" approach is that it is sensitive to outliers, because the CRS frontier can be spanned by a few (extreme) observations. This drawback can be reduced by using appropriate techniques such as order- $m$ (Cazals et al., 2002) or order- $\alpha$ (Aragon et al., 2005).

The accuracy of the residual approach to approximate the gradient of the frontier depends on the "step-size", i.e. the gap $S I C_{t}^{o}$ and $S I C_{t+1}^{o}$ between the frontier projections of $\mathbf{x}_{t}$ and $\mathbf{x}_{t+1}$ for the decomposition using output directions. The larger the step-size, the cruder the approximation. ${ }^{9}$ Thus, a big change in inputs for a DMU from period $t$ to period $t+1$ can give a cruder approximation of the frontier's gradient.

As a final remark, observe that both $\Delta T_{t, t+1}^{o}$ and $\Delta S E C_{t, t+1}^{o}$ are the arithmetic average of a Laspeyres (using base period $t$ ) and a Paasche (using base period $t+1)$ type indicator.

\footnotetext{
${ }^{9}$ This step-size is analogous to $h$ in the commonly used definition of a derivative of a function $f: f^{\prime}(x)=\lim _{h \rightarrow 0} \frac{f(x+h)-f(x)}{h}$. The more $h$ approaches zero, the better the approximation of the derivative at the evaluated point. Likewise, the smaller $S I C_{t}^{o}$ and $S I C_{t+1}^{o}$, the better the approximation of the frontier's gradient.
} 


\section{Empirical application: U.S. agriculture}

We investigate LHM TFP growth of U.S. agriculture across 48 states $^{10}$. We use our newly developed LHM decomposition to determine the main drivers of productivity growth. Specifically, we investigate the extent to which LHM TFP growth is driven by output growth and input growth, on the one hand, and technical change, technical inefficiency change and scale inefficiency change, on the other hand.

4.1. Data description. We use U.S. state-level agricultural panel data compiled by the U.S. Department of Agriculture (USDA). The data ranges from 1960 to 2004 and includes prices and quantities for 3 outputs (crops, livestock and other) and 4 inputs (land, intermediate, capital and labor). Table 1 contains mean values and the coefficient of variation per subperiod of 11 years. A full description of the data can be found in USDA (2016). The summary statistics suggest that aggregate production has substantially increased. Aggregate use of land, labor and to a lesser extent capital have decreased, while aggregate intermediate input use has increased. The low coefficient of variation of land use reveals that this production factor cannot be adjusted instantaneously.

\footnotetext{
${ }^{10}$ The dataset does not include data from Alaska and Hawaii.
} 


\begin{tabular}{|c|c|c|c|c|c|c|c|c|c|c|c|c|}
\hline & eriod & & Pacific & Mountain & orthern Plains & uthern Plains & Corn Belt & Southeast & Northeast & Lake States & ppalachian & Delta States \\
\hline \multirow{8}{*}{ Land } & \begin{tabular}{|l|}
$1960 / 71$ \\
\end{tabular} & ean & 00931.169 & 7255411.046 & 5840331.457 & 6292994.186 & 5004879.143 & 2215366.354 & 1768427.738 & 2444184.002 & 356925.337 & 1520081.600 \\
\hline & & C & 0.041 & 0.039 & 0.007 & 0.010 & 0.007 & 0.070 & 0.107 & 0.043 & 0.056 & 0.029 \\
\hline & $1971 / 82$ & Mean & 2893980.439 & 6720070.751 & 5687708.224 & 5781558.555 & 4767466.397 & 1773007.009 & 94621.216 & 99276.592 & 956513.091 & 343990.332 \\
\hline & & $\mathrm{CV}$ & 0.015 & 0.007 & 0.011 & 0.017 & 0.009 & 0.027 & 0.014 & 0.014 & 0.021 & 0.016 \\
\hline & $1982 / 93$ & Mean & 142.283 & 88197.735 & 5544756.703 & 5535859.150 & 4632340.008 & 1484494.228 & 267039.795 & 12296.486 & 818028.473 & 206858.098 \\
\hline & & & 0.029 & 0.011 & 0.004 & 0.004 & 0.011 & 0.067 & 0.055 & 0.024 & 0.030 & 0.039 \\
\hline & $1993 / 04$ & Mean & 90402.638 & 77026.474 & 31123.690 & 8432.955 & $\$ 2192.192$ & 1428024.529 & 90460.233 & 85066.363 & 302684.458 & 1209153.491 \\
\hline & & $\mathrm{CV}$ & 0.016 & 0.035 & 0.005 & 0.011 & 0.007 & 0.020 & 0.021 & 0.009 & 0.013 & 0.018 \\
\hline \multirow{8}{*}{ Intermediate } & 71 & Mean & 388062.631 & 74177.714 & 20391.093 & 5551339.202 & 16939475.421 & 22275.998 & 803636.777 & 70759.798 & 824174.845 & 446989.032 \\
\hline & & & 7 & 0.125 & 2 & 0.126 & 0.048 & 19 & 0.034 & 0.027 & 64 & 125 \\
\hline & $71 / 82$ & an & 6312.374 & 23653. & 11783582.906 & 5959.230 & 20865.969 & 5445467.048 & 43208.149 & 28635.249 & 70043.712 & 755.132 \\
\hline & & C) & 0.111 & 0.091 & 0.128 & 0.094 & 0.074 & 0.112 & 0.090 & 0.112 & 0.093 & 0.086 \\
\hline & 1982/93 & Mean & 8462752.863 & 6899795.667 & 12869397.188 & 7703305.897 & 16985319.256 & 5663158.403 & 12198.784 & 9970093.780 & 5939957.239 & 40621.090 \\
\hline & & & & & & & & & & & & 0.130 \\
\hline & $3 / 04$ & an & 11556159 & 73898 & 14492935.479 & 8891404 & 7845564.638 & 24523 & 77658 & 068114.621 & 96907.296 & .879 \\
\hline & & & & & & 0.064 & & & 0.054 & 0.059 & 0.119 & 0.031 \\
\hline \multirow{8}{*}{ Capital } & $0 / 7$ & Mean & 278.160 & 843.390 & 12.101 & 331.367 & 312.020 & 350.653 & 049.666 & 61.165 & 447.895 & 072.627 \\
\hline & & & & & & 0.056 & 0.084 & 0.070 & 0.021 & 0.030 & 0.067 & 0.115 \\
\hline & $1 / 82$ & Mean & 83856.991 & 2443132 . & 4662093.957 & 3052573.8 & 9993671.366 & 54854 & 40945 & 91432. & 33950.577 & 18949.272 \\
\hline & & & & & 0.072 & & 0.095 & 0.103 & 0.068 & & & \\
\hline & $1982 / 93$ & Mean & 5 & 2292679 . & 4213514.172 & 2901421.560 & 8602936.055 & 1665912.719 & 13.433 & 26726 . & 43 & 276 \\
\hline & & C) & 0.128 & & 0.108 & 0.108 & 0.159 & 0.147 & 0.124 & 0.131 & 0.141 & 0.144 \\
\hline & 1993/04 & Mean & 1983069.814 & 1936337.760 & 6963.177 & 6924.548 & 6070538.603 & 1370479.997 & 33837.703 & 62676.158 & 61032.305 & 1264252.022 \\
\hline & & & & & & & & & & & & 0.020 \\
\hline \multirow{8}{*}{ Labor } & & an & 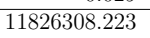 & 927 & 451651.8 & 557 & 26640405.728 & 2 & 331 & 1 & & .246 \\
\hline & & & & & & 0.141 & 0.164 & & & & 171 & 192 \\
\hline & $1 / 82$ & Mean & 62405.279 & 01263.1 & 21361.426 & 646.814 & 20171125.527 & 84264.056 & 55326.458 & 41201.345 & 925.952 & 45991.646 \\
\hline & & & & & & & 0.066 & & & & & 0.149 \\
\hline & $1982 / 93$ & & 9271807. & 6202223 . & 9061470. & 6519170 & 16138668.519 & 4774474 & 8008139. & 12006149 & 33646 & 99937 \\
\hline & & & & & & & & & & & & \\
\hline & $1993 / 04$ & Mean & 10210352.950 & 02355.190 & 1823.093 & 374.727 & 39104.652 & 3279.813 & 9996.042 & 357.592 & 745.715 & 1548.411 \\
\hline & & CI & & & & & & & & & 50 & 0.059 \\
\hline \multirow{8}{*}{ Crops } & $0 / 71$ & & 85 . & 806 & 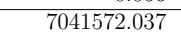 & 994 & 554.967 & - & 14. & 17. & 9 & 5 \\
\hline & & & ) & 0 & & 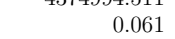 & 年 & 0 & tit. & 17. & 0 & 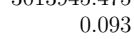 \\
\hline & & & 542. & 955 & 731. & 100 & $=$ & 424 & 512 & 250. & & \\
\hline & & C) & 0.157 & & 0. & 0. & 0.1 & & & 0.179 & 0.085 & 0.134 \\
\hline & $2 /$ & Mean & 43771.9 & 1908. & 6711 . & 907. & 994725.677 & 7229992 & 31209 & 86991. & 92866 & 2 \\
\hline & & & & & & & & & & & & 0.131 \\
\hline & 1993/04 & & 23286483. & 7886660 . & 16120799.9 & 193. & 27046336.520 & 8590499.524 & 5693994.670 & 12044270.033 & 004.214 & 5409819.779 \\
\hline & & & & & & & & & & & & \\
\hline \multirow{8}{*}{ Livestock } & $7 / 11$ & Mean & 884 & 007 & 314. & 132. & 320 & 32 & 852 & 337 & 337 & 39895 \\
\hline & & & & & & & & & & & & \\
\hline & & & 191.657 & 074. & 170.2 & 860.962 & 608.437 & 833. & 471. & 08. & 46.811 & 67.268 \\
\hline & & C & 0.044 & & 0.1 & 0.031 & 0.047 & 0. & 0. & 3 & 0.069 & 0.028 \\
\hline & $1982 / 93$ & Mean & 93949.676 & 6568411. & 65093.3 & 9950.726 & 14086364.477 & 6324043. & 1591. & 1877.289 & 3033.353 & 10247.573 \\
\hline & & Cl & & & & & & & & & & \\
\hline & & & 007 . & 8609192 & 105247 & 376. & 2438 & 9618 & $c$ & 06374 & 2 & 5279 \\
\hline & & & & & & & & & & & & 048 \\
\hline \multirow{8}{*}{ Other } & \begin{tabular}{|l|}
$1960 / 71$ \\
\end{tabular} & & 55214.023 & 754115.2 & 763723.7 & 528.6 & 973630.348 & 452. & 393. & 4042.9 & 1465.964 & 86.261 \\
\hline & & & & & & & & & & & & \\
\hline & $/ 82$ & & 7921. & 565772 & 433. & 874. & 779303 & 393 & 6832 & 0656 . & 338 & 9 \\
\hline & & C) & & & & & & & & & & \\
\hline & & Mean & 910.125 & 193.737 & 0545.782 & 2035.393 & 843864.319 & 9125. & 1187.178 & 790.108 & 187.411 & 379.070 \\
\hline & & $\mathrm{CV}$ & 0.121 & & 0.136 & 0.175 & 0.171 & 0.193 & 0.091 & 0.126 & 0.295 & 0.408 \\
\hline & $3 / 04$ & Mer & 2550514.545 & 1351626.26 & 47.71 & 3.994 & 92.400 & 82.468 & 59.874 & 55.293 & 0.724 & 1.059 \\
\hline & & & 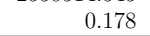 & 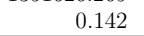 & 013 & & 0100 & 023 & $20-2$ & 018 & 0.216 & 012 \\
\hline
\end{tabular}

TABLE 1. Mean and coefficient of variation (CV) for quantities per subperiod in 1996 US dollars $\left(\times 10^{3}\right)$. 
The USDA identifies 10 regions of agricultural production in the U.S. An overview is provided in Table 2.

\begin{tabular}{|l|l|}
\hline Region & States \\
\hline Pacific & CA, OR, WA \\
Mountain & AZ, CO, ID, MT, NM, NV, UT, WY \\
Northern Plains & KS, ND, NE, SD \\
Southern Plains & OK, TX \\
Corn Belt & IA, IL, IN, MO, OH \\
Southeast & AL, FL, GA, SC \\
Northeast & CT, DE, MA, MD, ME, NH, NJ, NY, PA, RI, VT \\
Lake States & MI, MN, WI \\
Appalachian & KY, NC, TN, VA, WV \\
Delta States & AR, LA, MS \\
\hline
\end{tabular}

TABLE 2. Regions of agricultural production

We compute LHM TFP growth and its output-oriented decomposition for every state over the selected time period. We compare across all 48 states when computing the necessary distance functions and thus assume that all states have access to a similar production technology. This is also the approach of Zofío and Lovell (2001) and Ball et al. (2010). Alternatively, we could compare states within the same agricultural region (see Table 2). However, this would limit the set of observations to 2 or 3 for some regions, which may be insufficient. ${ }^{11}$

We first conduct the analysis for a non-convex technology (using Free Disposal Hull under a variable-returns-to-scale assumption) and then repeat the analysis for a convex technology (using Data Envelopment Analysis under a variable-returnsto-scale assumption). This shows the applicability of our decomposition for both technologies and highlights potential differences that can arise due to convexity assumptions of the production technology.

4.2. Non-convex technology. In practice, $\mathcal{Y}_{t}$ is unknown and needs to be estimated from the $K$ observations in the dataset. The smallest enveloping non-convex approximation under variable-returns-to-scale (VRS) is given by:

$$
\hat{\mathcal{Y}}_{t}=\left\{\left(\mathbf{x}_{0 t}, \mathbf{y}_{0 t}\right) \mid \sum_{k=1}^{K} \lambda_{k} \mathbf{x}_{k t} \leq \mathbf{x}_{0 t}, \sum_{k=1}^{K} \lambda_{k} \mathbf{y}_{k t} \geq \mathbf{y}_{0 t}, \sum_{k=1}^{K} \lambda_{k}=1, \lambda_{k} \in\{0,1\}\right\}
$$

and can be plugged in (1) to compute the directional distance function in practice. The resulting program is a mixed-integer program and can be computationally harder to solve than the usual linear program. As first pointed out by Tulkens

\footnotetext{
${ }^{11}$ O'Donnell (2012b) applies window analysis to circumvent this problem, but uses rather large windows for some regions. This can dampen the estimated rates of technical change.
} 
(1993), there exists an equivalent formulation based on enumeration which is considerably easier to solve. The enumeration formulation for directional distance functions with $\mathbf{g}_{t}>0$ proposed by Cherchye et al. (2001) is:

$$
D_{b}\left(\mathbf{x}_{0 a}, \mathbf{y}_{0 a} ; \mathbf{g}_{a}\right)=\max _{k \in\{1, \ldots, K\}}\left\{\min _{\substack{j \in\{1, \ldots, m\} \\ v \in\{1, \ldots, n\}}}\left\{\frac{Y_{k b}^{j}-Y_{0 a}^{j}}{g_{a}^{o j}}, \frac{X_{0 a}^{v}-X_{k b}^{v}}{g_{a}^{i v}}\right\}\right\},
$$

with $(a, b) \in\{t, t+1\} \times\{t, t+1\}$. This allows us to compute all distance functions needed for the LHM TFP indicator and its decomposition. In line with the literature, we choose $\mathbf{g}_{a}^{i}=\mathbf{x}_{0 a}$ and $\mathbf{g}_{a}^{o}=\mathbf{y}_{0 a}$ such that $\beta$ can be interpreted as the maximum proportional expansion (contraction) in the output (input) direction. ${ }^{12}$ Since we work with aggregate data, all of our chosen directional vectors are nonzero. Moreover, the data set only contains nonnegative outputs $\mathbf{y}_{t} \in \mathbb{R}_{+}^{m}$. As a result, we can use the simplified formula (14). ${ }^{13}$

4.2.1. Main findings for the U.S. We first present the results for the U.S. as a whole before presenting individual results for the agricultural regions. We first consider the average LHM TFP change in Figure 4. This is computed in a given year by taking the average LHM TFP of all states. This figure shows several considerable LHM TFP changes over time. Until 1979 - 1980, bad years offset good years resulting in only marginal cumulative LHM TFP growth over this period. After this period, positive growth rates dominate negative growth rates resulting in a positive cumulative LHM TFP growth of $78.61 \%$ in 2004 . This boils down to an average LHM TFP growth of $1.79 \%$ per year.

Figure 5 also shows the underlying drivers of these trends. Up to $1979-1980$, cumulative LHM TFP growth is driven by $L I_{t, t+1}$. Subsequently, both input decline and output growth contribute to substantial LHM TFP growth. Cumulative output growth is $44.10 \%$, while cumulative input decline is $34.51 \%$. This means that U.S. agricultural production simultaneously increases output production at an average rate of $1 \%$ per year while decreasing input use at an average rate of $0.78 \%$ per year.

We now turn to our LHM TFP decomposition. Technical progress is the main driver of LHM TFP growth which is partly offset by scale inefficiency growth. Over the entire period, technical progress increased with $139.57 \%$ on average while cumulative scale inefficiency change reached $-60.63 \%$. Technical inefficiency change

\footnotetext{
${ }^{12}$ This choice of the direction vector takes into account state heterogeneity and projects each observation in a different direction onto the frontier. Recently, more advanced data-driven approaches were developed that determine the direction vectors using the analyzed firm's configuration (see Daraio and Simar (2016) for technical details and Epure (2016) for a management-oriented discussion). Finally, a homogeneous direction vector is more desirable, for example, for regulators in sectors where heterogeneity in input-output configurations is low.

${ }^{13}$ We use Bogetoft and Otto (2015)'s Benchmarking package in R to compute the distance functions.
} 
plays virtually no role. Table 3 summarizes these results and also lists the minimal and maximal values of the LHM TFP indicator and its components per subperiod of 11 years. It also lists the corresponding states.

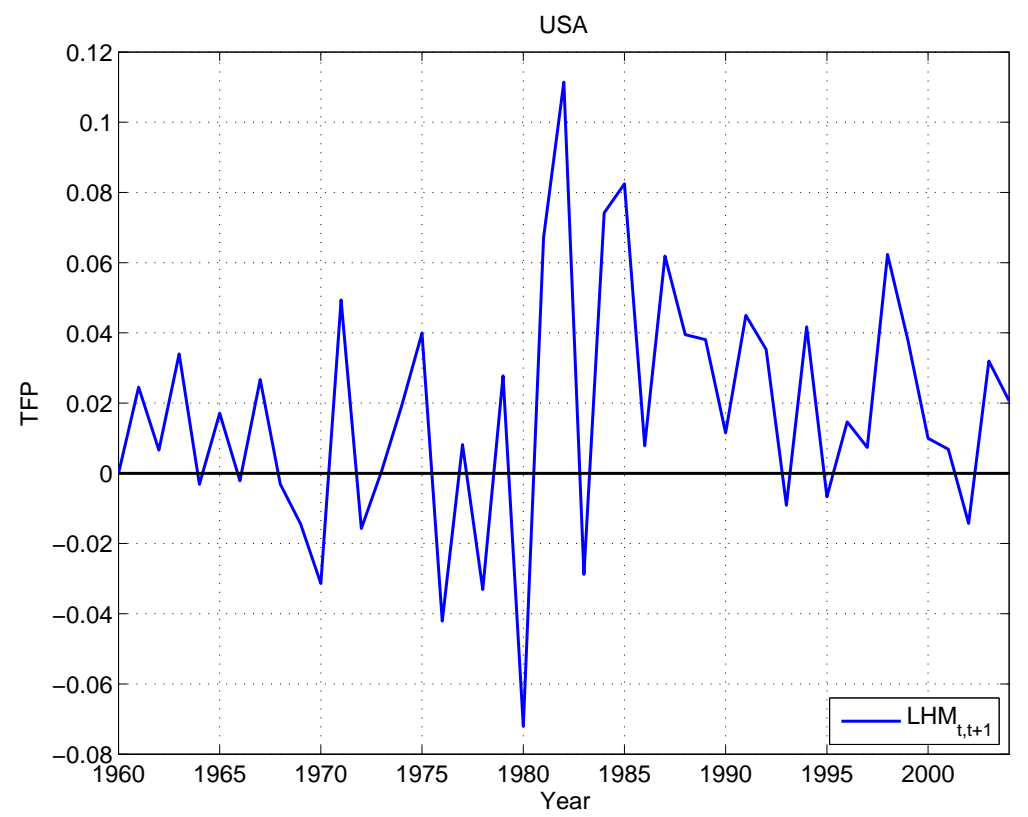

FigURE 4. Mean TFP change in the U.S. using a non-convex technology

\begin{tabular}{|ll|rrrrrr|}
\hline & & $L H M_{t, t+1}$ & $L O_{t, t+1}$ & $L I_{t, t+1}$ & $\Delta T_{t, t+1}^{o}$ & $\Delta T E I_{t, t+1}^{o}$ & $\Delta S E C_{t, t+1}^{o}$ \\
\hline$\sum_{t=1960}^{2004}$ mean(states) & & 78.61 & 44.10 & -34.51 & 139.57 & -0.32 & -60.63 \\
Avg growth rate & & 1.79 & 1.00 & -0.78 & 3.17 & $-7.30 \times 10^{-3}$ & -1.38 \\
\hline \multirow{4}{*}{$\min$} & $1960 / 71$ & $-5.72(\mathrm{OK})$ & $-4.70(\mathrm{OK})$ & $-6.61(\mathrm{RI})$ & $-8.77(\mathrm{FL})$ & $-1.45(\mathrm{OK})$ & $-30.20(\mathrm{RI})$ \\
& $1971 / 82$ & $-1.99(\mathrm{WY})$ & $-1.18(\mathrm{IN})$ & $-2.46(\mathrm{SC})$ & $-13.81(\mathrm{AZ})$ & $-0.57(\mathrm{PA})$ & $-7.95(\mathrm{DE})$ \\
& $1982 / 93$ & $0.30(\mathrm{FL})$ & $-2.02(\mathrm{SD})$ & $-4.76(\mathrm{NH})$ & $-1.22(\mathrm{AR})$ & $-0.28(\mathrm{MO})$ & $-14.44(\mathrm{NH})$ \\
& $1993 / 04$ & $-1.03(\mathrm{VT})$ & $-0.60(\mathrm{WY})$ & $-3.11(\mathrm{MA})$ & $-3.38(\mathrm{AL})$ & $-1.40(\mathrm{OK})$ & $-10.13(\mathrm{DE})$ \\
\hline \multirow{3}{*}{$\max$} & $1960 / 71$ & $3.29(\mathrm{RI})$ & $2.99(\mathrm{NV})$ & $2.02(\mathrm{CO})$ & $33.49(\mathrm{RI})$ & $0.00($ all but OK) & $9.68(\mathrm{FL})$ \\
& $1971 / 82$ & $3.90(\mathrm{OK})$ & $4.12(\mathrm{NE})$ & $2.98(\mathrm{ID})$ & $7.64(\mathrm{NH})$ & $1.45(\mathrm{OK})$ & $14.60(\mathrm{AZ})$ \\
& $1982 / 93$ & $7.45(\mathrm{UT})$ & $4.13(\mathrm{AR})$ & $1.42(\mathrm{OK})$ & $17.79(\mathrm{NH})$ & $0.57(\mathrm{PA})$ & $6.81(\mathrm{UT})$ \\
& $1993 / 04$ & $5.34(\mathrm{MA})$ & $5.42(\mathrm{SC})$ & $1.99(\mathrm{TN})$ & $13.76(\mathrm{DE})$ & $0.28(\mathrm{MO})$ & $7.61(\mathrm{AL})$ \\
\hline
\end{tabular}

TABLE 3. LHM TFP growth and its components in the U.S. over 1960 - 2004 (in \%) using a non-convex technology

4.2.2. Main findings per region. Figure 6 depicts the average cumulative LHM TFP and its components for every region over time. The mean is computed with respect to all states in that particular agricultural production region. The highest cumulative TFP growth is achieved by the Northeast, Southeast, Corn Belt and Delta States with $84.47 \%-95.62 \%$. They are followed by the Pacific, Northern Plains, Appalachian, Lake States and Mountain regions with 63.56\% - 74.36\%. 


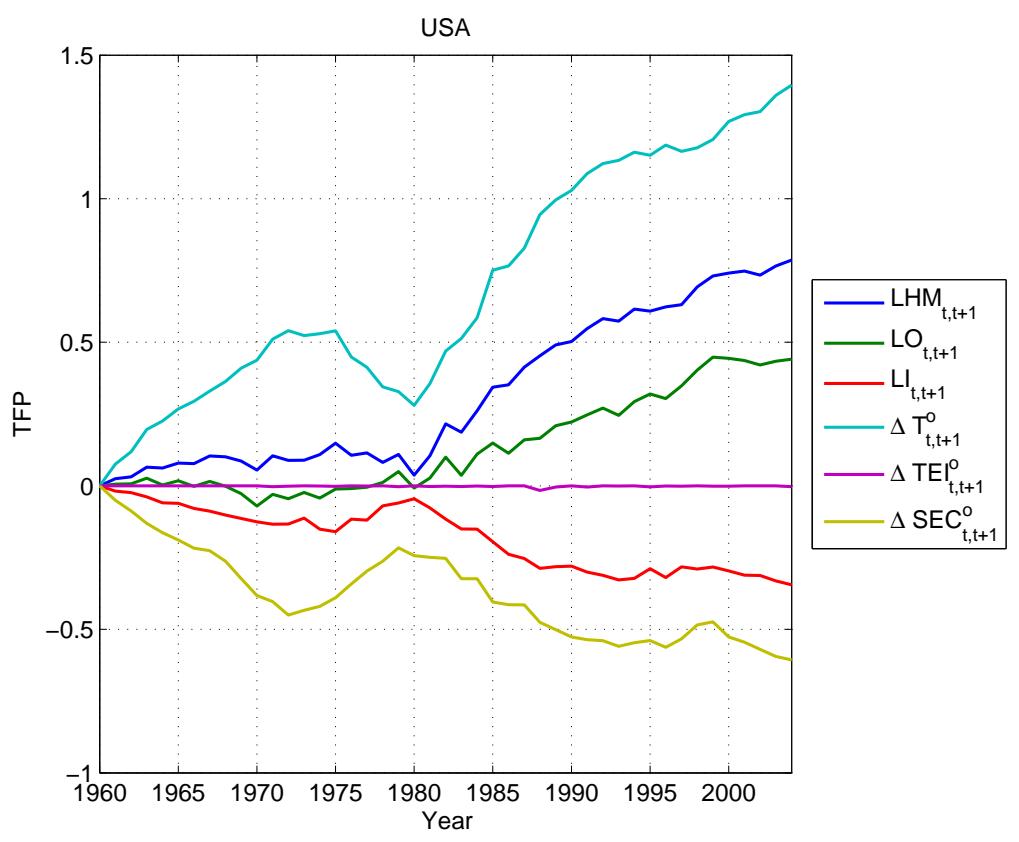

FiguRE 5. Mean cumulative TFP growth in the U.S. and it components using a non-convex technology

Finally, the Southern Plains region is severely behind the other regions with a cumulative TFP growth of $35.95 \%$.

Although almost all regions experience technical progress, there are diverging trends among the different regions. Positive (negative) cumulative technical change over the whole time period indicates progress (regress) in terms of production technology. The Northeast experienced the largest cumulative technical progress (349\%). The Pacific region is second with $162.2 \%$ and the Lake States are third with 104.9\%. The Mountain, Corn Belt, Appalachian, Northern Plains, Delta States and Southeast experience milder technical progress between $49.23 \%-83.65 \%$. The Southern Plains is the only region with a cumulative technical regress of $11.42 \%$, mainly due to a severe dip in the period $1975-1980$ from which it only slowly recovers.

Technical inefficiency change generally plays a minor role. Positive (negative) cumulative technical inefficiency change indicates that the distance to the frontier decreases (increases) over the whole time period. Negative changes in cumulative technical inefficiency change are quickly followed by positive changes. These spikes are visible in the Southern Plains, Northern Plains, Corn Belt, Delta States and Lake States. There is only a negative cumulative technical inefficiency change in the Southern Plains, due to a drop in technical inefficiency by $7.71 \%$ in 2004 . 
The trend in the scale inefficiency change is the mirror image of the trend in technical change: regions with positive (negative) technical change experience negative (positive) scale inefficiency. Positive (negative) cumulative scale inefficiency change indicates that the region operates at a more (less) optimal scale over the whole time period. The Southern Plains, Southeast, Delta States, Northern Plains, Corn Belt experience the highest positive cumulative scale inefficiency change between $4.48 \%-55.07 \%$. Cumulative scale inefficiency change is negative in the Appalachian, Mountain and Lake States (between $-1.00 \%$ and $-36.05 \%$ ). Cumulative scale inefficiency change is most negative in the Pacific $(-87.82 \%)$ and Northeast $(-253.4 \%)$ regions.

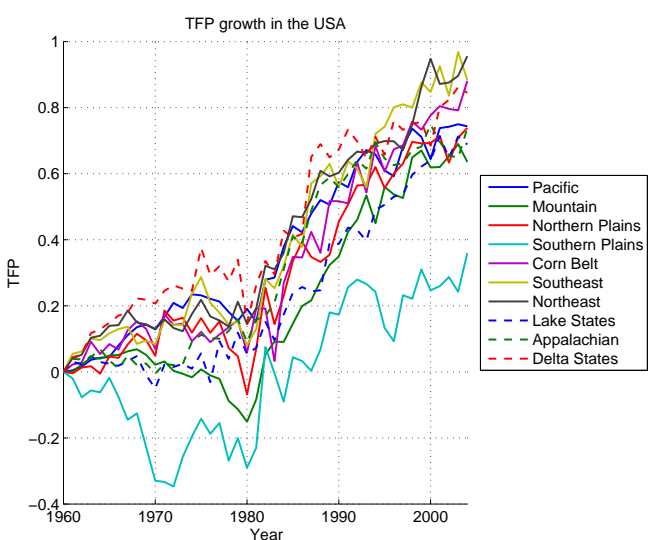

(A) Mean TFP growth

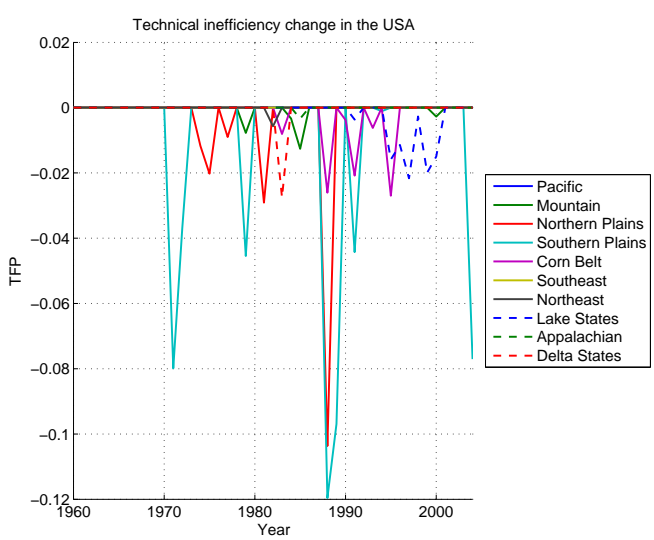

(c) Mean technical inefficiency change

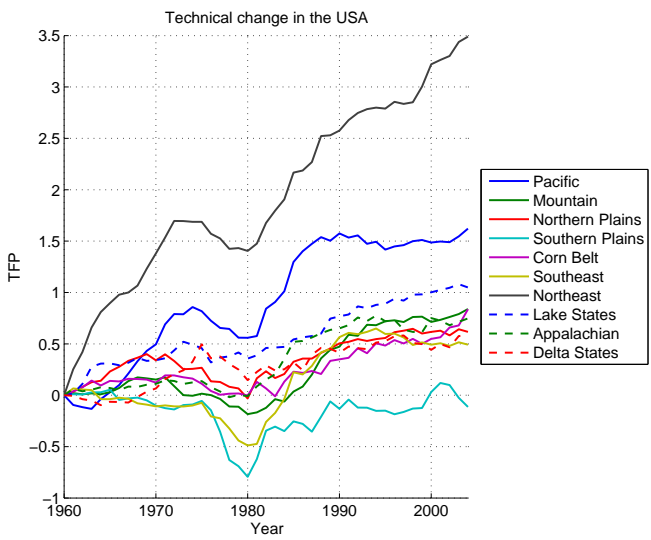

(B) Mean technical change

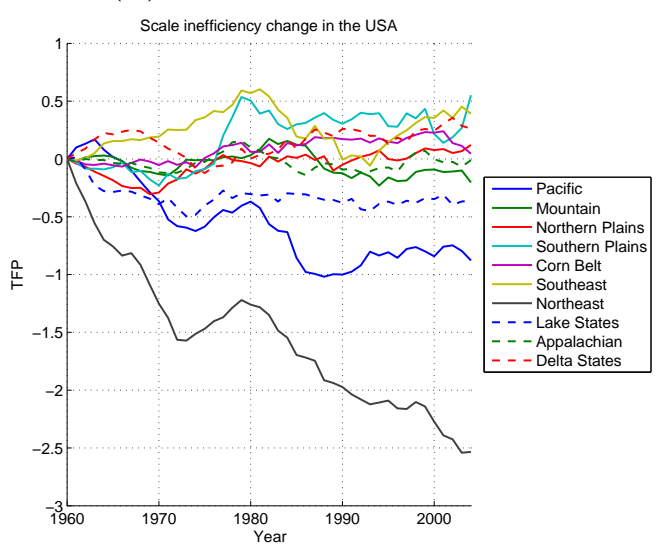

(D) Mean scale inefficiency change

FiguRE 6. TFP and its decomposition per U.S. region using a nonconvex technology

4.3. Convex technology. Since we only have 48 observations per year, a nonconvex technology might provide limited discriminating power resulting in many 
efficient observations. Therefore, we repeat the analysis for a convex VRS representation of the production technology using Data Envelopment Analysis (DEA). The smallest enveloping approximation is given by:

$$
\hat{\mathcal{Y}}_{t}=\left\{\left(\mathbf{x}_{0 t}, \mathbf{y}_{0 t}\right) \mid \sum_{k=1}^{K} \lambda_{k} \mathbf{x}_{k t} \leq \mathbf{x}_{0 t}, \sum_{k=1}^{K} \lambda_{k} \mathbf{y}_{k t} \geq \mathbf{y}_{0 t}, \sum_{k=1}^{K} \lambda_{k}=1, \lambda_{k} \geq 0\right\},
$$

and can be plugged in (1) to compute the directional distance function in practice. The resulting linear program with $(a, b) \in\{t, t+1\} \times\{t, t+1\}$ is:

$$
\begin{aligned}
D_{b}\left(\mathbf{x}_{0 a}, \mathbf{y}_{0 a} ; \mathbf{g}_{a}\right)=\max _{\beta, \lambda_{k} \geq 0} \beta \text { s.t. } & \sum_{k=1}^{K} \lambda_{k} \mathbf{x}_{k b} \leq \mathbf{x}_{0 a}-\beta \mathbf{g}_{a}^{i}, \\
& \sum_{k=1}^{K} \lambda_{k} \mathbf{y}_{k b} \geq \mathbf{y}_{0 a}+\beta \mathbf{g}_{a}^{o}, \\
& \sum_{k=1}^{K} \lambda_{k}=1 .
\end{aligned}
$$

This allows us to compute all necessary distance functions needed for all the components of the LHM TFP indicator. As for the FDH analysis, we choose $\mathbf{g}_{a}^{i}=\mathbf{x}_{0 a}$ and $\mathbf{g}_{a}^{o}=\mathbf{y}_{0 a}$.

4.3.1. Main findings for the U.S. We present the results for the U.S. as a whole before presenting individual results for the agricultural regions ${ }^{14}$. We first consider the average annual LHM TFP change in Figure 7. This is computed in a given year by taking the average LHM TFP of all states. This figure shows considerable fluctuations in annual LHM TFP changes over time. Overall, years with LHM TFP growth dominate years with LHM TFP decline.

Figure 8 shows the cumulative LHM TFP growth and the underlying drivers. Our main finding for the U.S. as a whole is that LHM TFP clearly increases over time. The LHM TFP indicator increases by $70.46 \%$ between 1960 and 2004. This boils down to an average LHM TFP growth of $1.60 \%$ per year. LHM TFP growth is driven by output growth $(+62.98 \%)$ rather than input decline $(-7.47 \%)$. In the period $1977-1982, L I_{t, t+1}$ contributes to a temporary slowdown in LHM TFP growth. $L I_{t, t+1}$ only plays a minor role in the remaining periods.

We now turn to our LHM decomposition. Our decomposition shows that technical change $(+70.55 \%)$ is the main driver, while technical inefficiency change $(-1.99 \%)$ and scale inefficiency change $(+0.42 \%)$ only play a minor role. Table 4 summarizes

\footnotetext{
${ }^{14}$ Infeasibilities may arise for the components where the year of the observation differs from the year of the reference technology. As there is no easy solution to solve this problem, Briec and Kerstens (2009) recommend to report the infeasibilities. There were only infeasibilities for Rhode Island.
} 


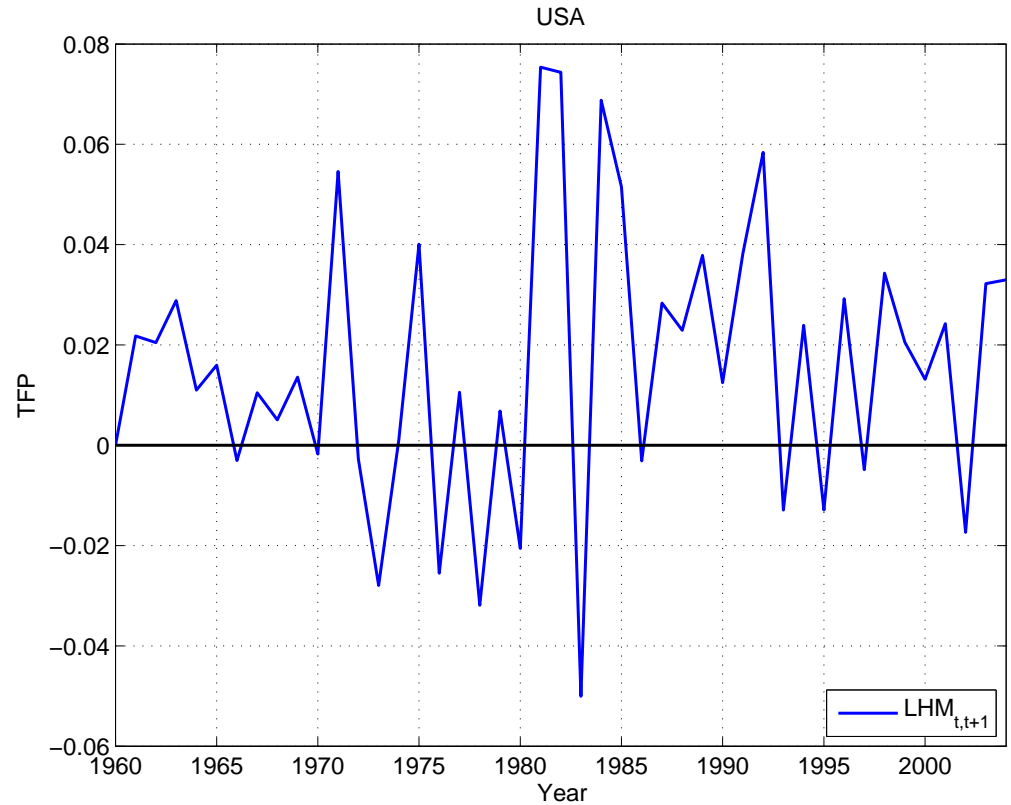

FiguRE 7. Mean TFP change in the U.S. using a convex technology

these results and lists the minimal and maximal values of the LHM TFP indicator and its components per subperiod of 11 years. It also lists the corresponding states.

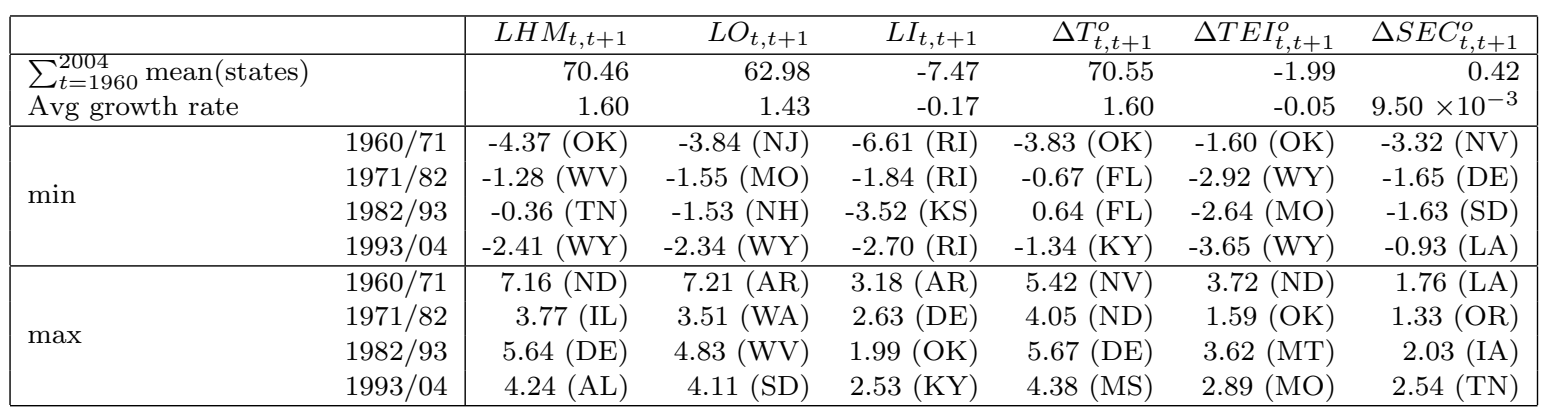

TABLE 4. TFP growth and its components in the U.S. covering the years $1960-2004$ (in \%) using a convex technology

4.3.2. Main findings per region. Figure 9 depicts the mean cumulative LHM TFP and its components for every region over time. The mean is computed with respect to all states in that particular agricultural production region. The Northern Plains experienced the highest cumulative LHM TFP growth $(119.3 \%)$ while the Southern Plains experienced the lowest cumulative LHM TFP growth (8.96\%) over the entire period. Between them, Delta States experience the second highest 


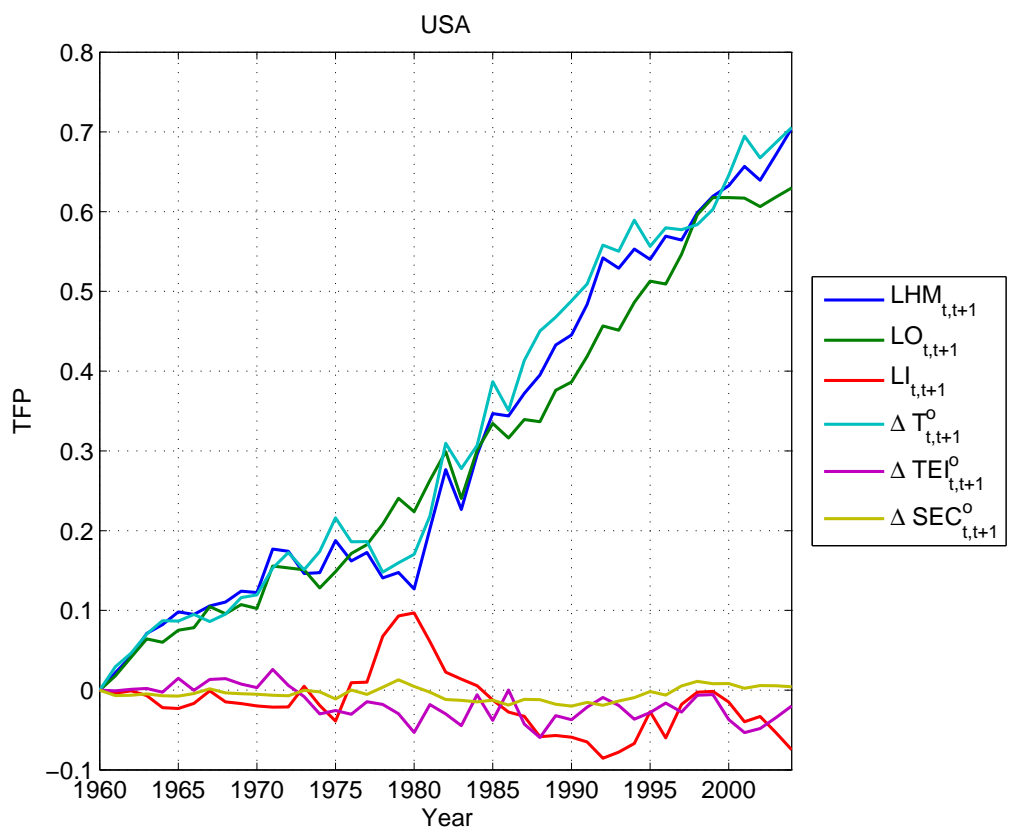

FiguRE 8. Mean cumulative TFP growth and its components in the U.S. using a convex technology

cumulative LHM TFP growth of $107 \%$. Pacific, Corn Belt, Southeast, Northeast and Mountain regions have similar levels of cumulative LHM TFP growth of $65.58 \%-86.18 \%$. The cumulative LHM TFP growth of Lake States and Appalachian regions varies in the range $35.36 \%-46.83 \%$.

Being the main driver of LHM TFP growth, similar trends occur for technical change. The Northern Plains region has the highest rate of cumulative technical change (117.9\%) and the Southern Plains the lowest (6.25\%). Again, Delta States experience the second highest rate of technical change of $95 \%$. The other regions can roughly be classified in two clusters. The first cluster consists of the Corn Belt, Mountain, Southeast, Pacific and Northeast regions $(63.89 \%-81.67 \%)$. The second cluster consists of Lake States and Appalachian (43.6\% - 52.09\%).

In terms of cumulative technical inefficiency change, there are diverging trends among the different regions. Pacific, Northern Plains, Delta States and Northeast experience a positive cumulative technical inefficiency change between $4.86 \%$ and $10.82 \%$. The six remaining regions experience a negative cumulative technical inefficiency change. Cumulative technical inefficiency change is mildly negative (between $-7.01 \%$ and $-1.58 \%$ ) in the Southeast, Corn Belt, Lake States and Mountain regions. This is worse in the Southern Plains and Appalachian, where the cumulative technical inefficiency change is $-12.96 \%$ and $-23.61 \%$, respectively.

Again, there are diverging trends for cumulative scale inefficiency change. The Southern Plains experience the highest increase in cumulative scale inefficiency 
change (15.67\%) followed closely by the Appalachian region (15.38\%). The Northern Plains experience a negative cumulative scale inefficiency change $(-9.5 \%)$. Between these extremes, the Pacific, Corn Belt, Delta States, Southeast and Lake States have a positive cumulative scale inefficiency change in the range of $1.29 \%-7.56 \%$. In contrast, the cumulative scale inefficiency change of the Northeast and Mountain regions is negative $(-6.64 \%$ and $-7.88 \%$, respectively).
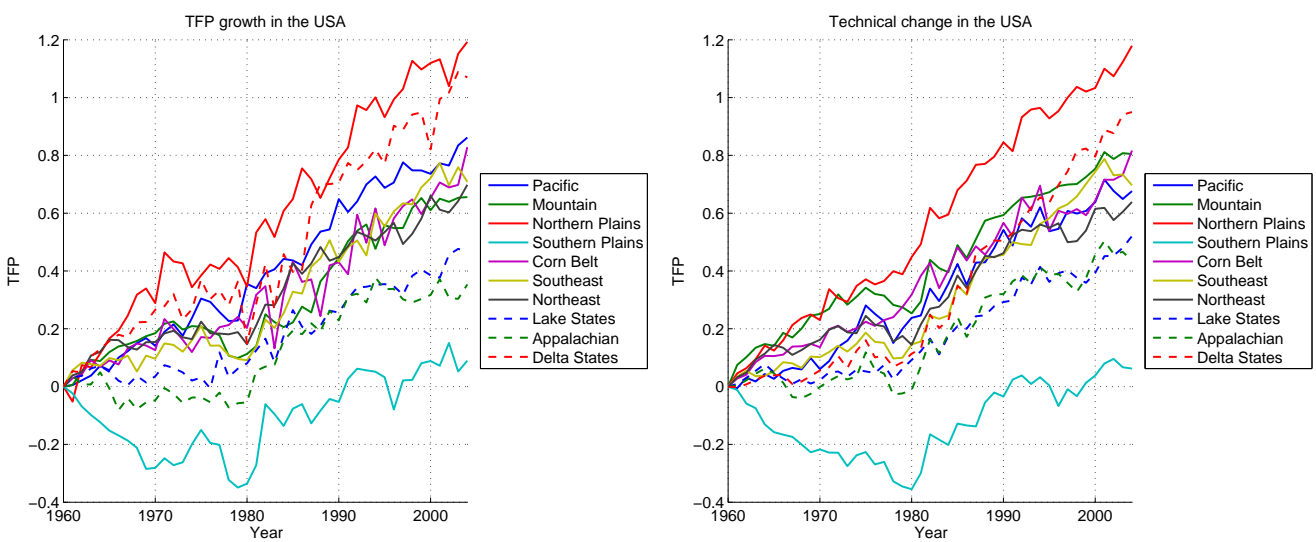

(A) Average cumulative TFP growth per region

(B) Average cumulative technical

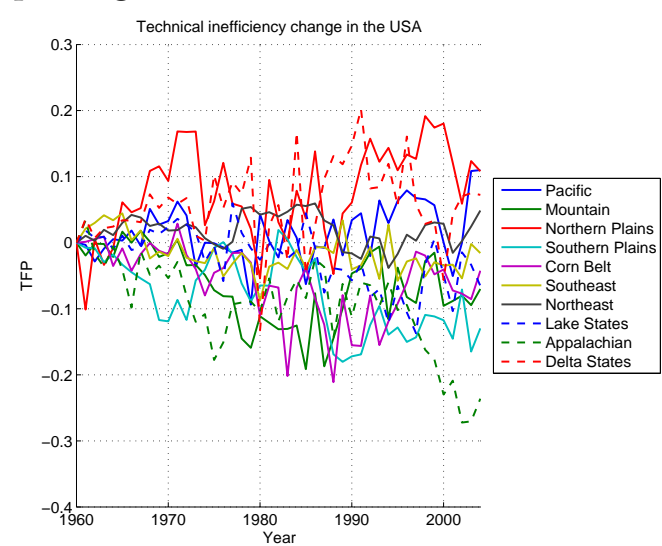

change per region

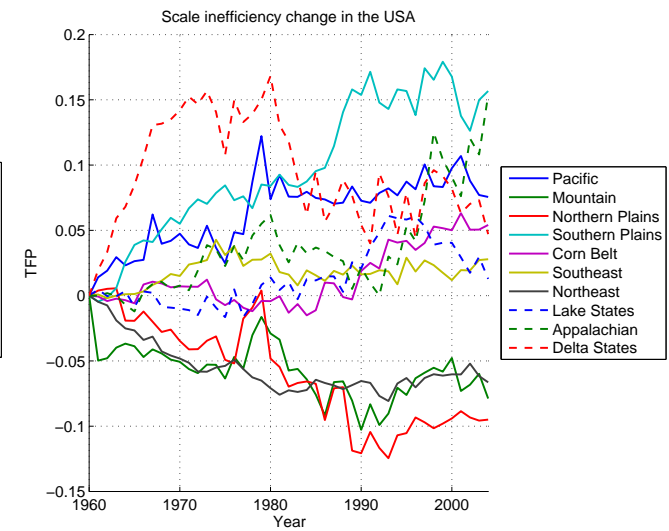

(C) Average cumulative technical inefficiency change per region

(D) Average cumulative scale inefficiency change per region

Figure 9. Cumulative TFP growth and its decomposition per U.S. region using a convex technology

Although all U.S. regions experienced LHM TFP growth in the period $1960-$ 2004 , this analysis shows that the contribution of the underlying factors varies considerably per region. Technical change is the main driver of LHM TFP growth for all U.S. regions. In addition, several U.S. regions partly increased TFP by 
becoming more efficient over time and/or operating at a more optimal scale. Other regions mainly relied on technical change to increase LHM TFP.

4.4. Discussion. The results depend on the convexity assumption of the technology. We test the hypothesis whether the distributions of the LHM TFP indicator and its components for FDH and DEA are not significantly different using a Kolmogorov-Smirnov test. This nonparametrically tests the hypothesis $H_{0}$ whether two samples are drawn from the same underlying distribution. We conduct the test for every year separately, resulting in 44 different test hypotheses for every component. The results at the $10 \%$ significance level are presented in Table 5. For the majority of years, the distributions of the $L H M_{t, t+1}$ and its components $L O_{t, t+1}$ and $L I_{t, t+1}$ are not statistically different using FDH and DEA. In contrast, the distributions of $\Delta T_{t, t+1}^{o}$ are statistically significant for a majority of years and the distributions of $\Delta T E I_{t, t+1}^{o}$ and $\triangle S E C_{t, t+1}^{o}$ under both technologies are significantly different for all years. These results in conjunction with Table 3 and Table 4 lead us to the following qualitative conclusions.

\begin{tabular}{|l|llllll|}
\hline & $L H M_{t, t+1}$ & $L O_{t, t+1}$ & $L I_{t, t+1}$ & $\Delta T_{t, t+1}^{o}$ & $\Delta T E I_{t, t+1}^{o}$ & $\Delta S E C_{t, t+1}^{o}$ \\
\hline Reject $H_{0}$ per year at $10 \%$ & $9 / 44$ & $12 / 44$ & $8 / 44$ & $25 / 44$ & $44 / 44$ & $44 / 44$ \\
Reject $H_{0}$ at $10 \%$ & No & Yes & Yes & Yes & Yes & Yes \\
\hline
\end{tabular}

TABLE 5. Results of Kolmogorov-Smirnov test testing equality of distributions under non-convex and convex technologies

Both results suggest there is substantial LHM TFP growth over the entire period which is mainly driven by technical progress. Both the DEA and FDH results indicate that output growth dominates input decline, although this finding is much more pronounced for the DEA results. A possible explanation for the smaller contribution of input decline is that some quasi-fixed inputs (e.g. land) are not constantly adjusted over time or that input reduction is not an objective for some inputs such as land and labor.

We analyze LHM TFP growth and technical change across time, farm types and agricultural intensity rates. Table 6 shows the results of the Kolmogorov-Smirnov test testing equality of distributions for LHM TFP growth rates and technical changes for consecutive subperiods of eleven years in line with Table 3. Regarding FDH, all distributions of consecutive LHM TFP growth rates and technical changes are significantly different at the $10 \%$ level. Regarding DEA, the distributions of the LHM TFP growth rates and technical changes between 1982/93 and 1993/04 are not significantly different at the $10 \%$ level, while these are significantly different comparing the preceding time periods. This suggests that distributional differences in productivity growth driven by shifts in technology may decrease in importance throughout time. 


\begin{tabular}{|l|lll|}
\hline & $1960 / 71-1971 / 82$ & $1971 / 82-1982 / 93$ & $1982 / 93-1993 / 04$ \\
\hline FDH: Reject $H_{0}$ at $10 \% L H M_{t, t+1}$ & Yes & Yes & Yes \\
FDH: Reject $H_{0}$ at $10 \% \Delta T_{t, t+1}$ & Yes & Yes & Yes \\
\hline DEA: Reject $H_{0}$ at $10 \% L H M_{t, t+1}$ & Yes & Yes & No \\
DEA: Reject $H_{0}$ at $10 \% \Delta T_{t, t+1}$ & Yes & Yes & No \\
\hline
\end{tabular}

TABLE 6. Results of Kolmogorov-Smirnov test testing equality of distributions for LHM TFP growth rates and technical changes for consecutive time periods

In line with Ang and Kerstens (2016), we assess whether there are distributional differences in LHM TFP growth rates and technical changes between farm types in Table 7. We rank the farm regions by the ratio of crop production to total production considering the whole time period. This leads to a classification of 3 crop regions (Corn Belt, Northern Plains and Pacific), 4 mixed regions (Delta States, Southeast, Appalachian, and Northeast) and 3 livestock regions (Lake States, Mountain area and Southern Plains). Regarding the FDH results, the distributions of the LHM TFP growth rates of mixed regions and livestock regions are significantly different at the $10 \%$ level, while these are not significantly different at the 10\% level comparing crop regions to mixed regions and livestock regions. Interestingly, regarding the FDH results, the distributions of the technical changes are significantly different at the $10 \%$ level comparing all types of regions. Regarding the DEA results, the distributions of the LHM TFP growth rates and technical changes of crop regions and mixed regions, and mixed regions and livestock regions, are not significant at the $10 \%$ level, while these are significantly different at the $10 \%$ level comparing crop regions to livestock regions. In summary, there seems to be ambiguity in how regional differences in specialization may drive differences in the distribution of LHM TFP growth and technical changes.

\begin{tabular}{|l|lll|}
\hline & Crops - Mixed & Mixed - Livestock & Crops - Livestock \\
\hline FDH: Reject $H_{0}$ at $10 \% L H M_{t, t+1}$ & No & Yes & No \\
FDH: Reject $H_{0}$ at $10 \% \Delta T_{t, t+1}$ & Yes & Yes & Yes \\
\hline DEA: Reject $H_{0}$ at $10 \% L H M_{t, t+1}$ & No & No & Yes \\
DEA: Reject $H_{0}$ at $10 \% \Delta T_{t, t+1}$ & No & No & Yes \\
\hline
\end{tabular}

TABLE 7. Results of Kolmogorov-Smirnov test testing equality of distributions between farm types for LHM TFP growth rates and technical changes covering the whole time period

We also assess whether there are distributional differences in LHM TFP growth rates and technical changes between agricultural intensity rates in Table 8. We rank the farm regions by the Industry Specialization Index (ISI) for agriculture 
considering $1963-2004^{15}$. The U.S. Bureau of Economic Analysis (BEA) computes the ISI as the agricultural industry's share of the state-level Gross Domestic Product divided by the agricultural industry's share of the U.S. total for the same statistic. The complete dataset can be found in BEA (2016). We rank the regions by ISI, which leads to a classification of 3 low ISI regions (Northeast, Lake States and Southeast), 4 medium ISI regions (Appalachian, Southern Plains, Pacific and Corn Belt) and 3 high ISI regions (Mountain area, Delta States and Northern Plains). With respect to the FDH results, comparing distributions of the LHM TFP growth rates for all groups do not yield any significant difference at the $10 \%$ level. The distributions of the technical changes are significantly different at the $10 \%$ level comparing low ISI regions to medium and high ISI regions. Regarding the DEA results, the distributions of the LHM TFP growth rates and technical changes are significantly different at the $10 \%$ level comparing medium ISI regions to high ISI regions. Similar to the preceding section, there thus seems to be ambiguity in how regional differences in agricultural intensity may drive differences in the distribution of LHM TFP growth and technical changes.

\begin{tabular}{|l|lll|}
\hline & Low - Medium & Medium - High & Low - High \\
\hline FDH: Reject $H_{0}$ at $10 \% L H M_{t, t+1}$ & No & No & No \\
FDH: Reject $H_{0}$ at $10 \% \Delta T_{t, t+1}$ & Yes & No & Yes \\
\hline DEA: Reject $H_{0}$ at $10 \% L H M_{t, t+1}$ & No & Yes & No \\
DEA: Reject $H_{0}$ at $10 \% \Delta T_{t, t+1}$ & No & Yes & No \\
\hline
\end{tabular}

TABLE 8. Results of Kolmogorov-Smirnov test testing equality of distributions between agricultural intensity rates for LHM TFP growth rates and technical changes covering the whole time period

The contribution of technical inefficiency change to LHM TFP growth is less clear-cut. Using FDH, technical inefficiency change is virtually nonexistent. Further inspection reveals that most (contemporaneous) technical inefficiency scores are zero using FDH. This drives the extremely low technical inefficiency change. Therefore, these remarkable results may be due to lower discriminatory power of $\mathrm{FDH}$ in this case since there are relatively few observations per year compared to the number of inputs and outputs. Using DEA, there is a small cumulative increase in technical inefficiency change.

The results differ more for the scale inefficiency change component. There is a substantial increase in cumulative scale inefficiency change using FDH, whereas there is almost no cumulative scale inefficiency change using DEA. Again, this may be due to the higher discriminatory power of DEA.

Our DEA results are in line with other empirical studies that analyze the TFP growth in the U.S. agricultural sector using the same data source. Zofío and Lovell

\footnotetext{
${ }^{15}$ Data for 1960 - 1962 are unavailable.
} 
(2001), Ball et al. (2010), O'Donnell (2012b) and Ball et al. (2016) also find substantial TFP growth ${ }^{16}$. It is driven by technical progress rather than efficiency change in line with Zofío and Lovell (2001) and Ball et al. (2016). Following Ball et al. (2016), TFP growth is also due to output growth rather than changes in the input level.

\section{Conclusions}

This paper decomposes the additively complete LHM TFP indicator into components of technical change, technical inefficiency change and scale inefficiency change. Our approach is general in that it does not require differentiability or convexity of the production technology. Using a nonparametric framework, the empirical application focuses on state-level data of the U.S. agricultural sector over the period $1960-2004$. We compute the scores using FDH and DEA to show the flexibility of our decomposition and to investigate the potential issue of nonconvexities in the agricultural sector. Furthermore, we analyze LHM TFP growth and technical change across time, farm types and agricultural intensity rates.

The FDH results show that LHM TFP has increased by $78.61 \%$ in the considered period. This is due to output growth $(+44.10 \%)$ as well as input decline $(-34.51 \%)$. Technical change $(+130.57 \%)$ and scale inefficiency change $(-60.63 \%)$ are the main drivers, while technical inefficiency change $(-0.32 \%)$ only plays a minor role.

Following the DEA results, LHM TFP has increased by $70.46 \%$ for the considered period. This productivity growth is due to output growth $(+62.98 \%)$ rather than changes in the input level $(-7.47 \%)$. Technical change is the main driver $(+70.55 \%)$, while technical inefficiency change $(-1.99 \%)$ and scale inefficiency change $(+0.42 \%)$ only play a minor role.

The results thus depend on whether we use FDH or DEA. Although this may partly be driven by the underlying true production technology, we note that FDH may result in too low discriminatory power to compute the distance functions given the relatively low number of observations for the number of variables in this application.

Following the Kolmogorov-Smirnov tests, there seem to be differences in the distributions of LHM TFP growth and technical change across time, farm types and agricultural intensity rates. We suspect that policy instruments and factor endowments (e.g. soil and weather conditions) may drive differences across time, farm types and agricultural intensity rates, potentially resulting in differing distributions in LHM TFP growth and technical change. For instance, agricultural support payments with restrictions on land use (Just and Kropp, 2013) and ethanol subsidies (Motamed et al., 2016) likely have an impact on geographical specialization.

\footnotetext{
${ }^{16}$ Zofío and Lovell (2001) only analyze TFP growth over the period $1960-1990$.
} 
This information would be relevant for policy makers. Such an empirical investigation is left for future research. 


\section{REFERENCES}

Ang, F. And P. J. Kerstens (2016): "To Mix or Specialise? A Coordination Productivity Indicator for English and Welsh farms," Journal of Agricultural Economics, 67, 779-798.

Aragon, Y., A. Daouia, And C. Thomas-Agnan (2005): "Nonparametric Frontier Estimation: A Conditional Quantile-Based Approach," Econometric Theory, 21, 358-389.

Balk, B. M., R. Färe, And S. Grosskopf (2003): "The theory of economic price and quantity indicators," Economic Theory, 23, 149-164.

BAll, E., S. L. WANG, AND R. Nehring (2016): "USDA ERS - Agricultural Productivity in the U.S." (Accessed on 2016-05-02).

Ball, V. E., R. Färe, S. Grosskopf, and D. Margaritis (2010): The Economic Impact of Public Support to Agriculture, New York, NY: Springer New York, chap. Productivity and Profitability of US Agriculture: Evidence from a Panel of States, 125-139.

Barros, C. P., A. Ibiwoye, And S. Managi (2008): "Productivity change of Nigerian insurance companies: 1994-2005," African Development Review, 20, $505-528$.

BEA (2016): "BEA," http://http://www.bea.gov/iTable/index_regional. cfm, (Accessed on 2016-12-01).

Buurek, H. (1996): "The Malmquist total factor productivity index," Scandinavian Journal of Economics, 303-313.

Bogetoft, P. (1996): "DEA on relaxed convexity assumptions," Management Science, 42, 457-465.

Bogetoft, P. And L. Отто (2015): Benchmarking with DEA and SFA, r package version 0.26 .

Briec, W. And K. Kerstens (2004): "A Luenberger-Hicks-Moorsteen productivity indicator: its relation to the Hicks-Moorsteen productivity index and the Luenberger productivity indicator," Economic Theory, 23, 925-939.

(2009): "Infeasibility and directional distance functions with application to the determinateness of the Luenberger productivity indicator," Journal of Optimization Theory and Applications, 141, 55-73.

Briec, W., K. Kerstens, And N. Peypoch (2012): "Exact relations between four definitions of productivity indices and indicators," Bulletin of Economic Research, 64, 265-274.

Briec, W. AND Q. B. Liang (2011): "On some semilattice structures for production technologies," European Journal of Operational Research, 215, 740-749.

Briec, W. AND N. PEYPOCH (2007): "Biased technical change and parallel neutrality," Journal of Economics, 92, 281-292.

Caves, D. W., L. R. Christensen, And W. E. Diewert (1982): "The economic theory of index numbers and the measurement of input, output, and productivity," Econometrica, 1393-1414. 
Cazals, C., J.-P. Florens, And L. Simar (2002): "Nonparametric frontier estimation: a robust approach," Journal of Econometrics, 106, 1 - 25.

Chambers, R. G. (2002): "Exact nonradial input, output, and productivity measurement," Economic Theory, 20, 751-765.

Chambers, R. G., R. FÄre, and S. Grosskopf (1996): "Productivity growth in APEC countries," Pacific Economic Review, 1, 181-190.

Cherchye, L., T. Kuosmanen, and T. Post (2001): "FDH directional distance functions with an application to European commercial banks," Journal of Productivity Analysis, 15, 201-215.

Daraio, C. AND L. Simar (2016): "Efficiency and benchmarking with directional distances: a data-driven approach," Journal of the Operational Research Society, 67, 928-944.

DiEWERT, W. E. (1976): "Exact and superlative index numbers," Journal of Econometrics, 4, 115-145.

Diewert, W. E. And K. J. Fox (2014): "Reference technology sets, Free Disposal Hulls and productivity decompositions," Economics Letters, 122, 238-242. (2017): "Decomposing productivity indexes into explanatory factors," European Journal of Operational Research, 256, 275 - 291.

Epure, M. (2016): "Benchmarking for routines and organizational knowledge: a managerial accounting approach with performance feedback," Journal of Productivity Analysis, 46, 87-107.

Epure, M., K. Kerstens, And D. Prior (2011): "Bank productivity and performance groups: A decomposition approach based upon the Luenberger productivity indicator," European Journal of Operational Research, 211, 630641.

Färe, R., S. Grosskopf, And D. Njinkeu (1988): "Note-On Piecewise Reference Technologies," Management Science, 34, 1507-1511.

Färe, R., S. Grosskopf, M. Norris, And Z. Zhang (1994): "Productivity growth, technical progress, and efficiency change in industrialized countries," American Economic Review, 66-83.

FÄre, R., S. Grosskopf, And P. Roos (1998): "Malmquist productivity indexes: a survey of theory and practice," in Index numbers: Essays in honour of Sten Malmquist, Springer, 127-190.

Grosskopf, S. (2003): "Some remarks on productivity and its decompositions," Journal of Productivity Analysis, 20, 459-474.

Just, D. R. And J. D. Kropp (2013): "Production Incentives from Static Decoupling: Land Use Exclusion Restrictions," American Journal of Agricultural Economics, 95, 1049-1067.

LuenBerger, D. G. (1992): "New optimality principles for economic efficiency and equilibrium," Journal of optimization theory and applications, 75, 221-264.

Managi, S. (2010): "Productivity measures and effects from subsidies and trade: an empirical analysis for Japan's forestry," Applied Economics, 42, 3871-3883. 
Motamed, M., L. McPhail, and R. Williams (2016): "Corn Area Response to Local Ethanol Markets in the United States: A Grid Cell Level Analysis," American Journal of Agricultural Economics, 98, 726-743.

NAKANo, M. AND S. MANAGI (2008): "Regulatory reforms and productivity: an empirical analysis of the Japanese electricity industry," Energy Policy, 36, 201-209.

O'Donnell, C. J. (2012a): "An aggregate quantity framework for measuring and decomposing productivity change," Journal of Productivity Analysis, 38, $255-272$.

(2012b): "Nonparametric estimates of the components of productivity and profitability change in US agriculture," American Journal of Agricultural Economics, 873-890.

Petersen, N. C. (1990): "Data envelopment analysis on a relaxed set of assumptions," Management Science, 36, 305-314.

Podinovski, V. (2005): "Selective convexity in DEA models," European Journal of Operational Research, 161, 552-563.

Tulkens, H. (1993): "On FDH Efficiency Analysis: Some Methodological Issues and Applications to Retail Banking, Courts, and Urban Transit," Journal of Productivity Analysis, 183-210.

USDA (2016): "USDA," http://www.ers.usda.gov/data-products/ agricultural-productivity-in-the-us.aspx, (Accessed on 2016-11-24).

Zofío, J. L. AND C. A. K. Lovell (2001): "Graph efficiency and productivity measures: an application to US agriculture," Applied Economics, 33, 1433-1442. 


\section{Appendix A. Managi (2010)'s DeComposition}

Managi (2010) decomposes the Luenberger-Hicks-Moorsteen indicator into technical change (TC):

$$
\begin{aligned}
T C & =\left[D_{t+1}\left(\mathbf{x}_{t+1}, \mathbf{y}_{t+1} ;\left(\mathbf{g}_{t+1}^{i}, 0\right)\right)-D_{t}\left(\mathbf{x}_{t+1}, \mathbf{y}_{t+1} ;\left(\mathbf{g}_{t+1}^{i}, 0\right)\right)\right] \\
& -\left[D_{t+1}\left(\mathbf{x}_{t+1}, \mathbf{y}_{t+1} ;\left(0, \mathbf{g}_{t+1}^{o}\right)\right)-D_{t}\left(\mathbf{x}_{t+1}, \mathbf{y}_{t+1} ;\left(0, \mathbf{g}_{t+1}^{o}\right)\right)\right],
\end{aligned}
$$

and the residual being efficiency change (EC):

$$
\begin{aligned}
E C & =\frac{1}{2}\left\{D_{t}\left(\mathbf{x}_{t}, \mathbf{y}_{t} ;\left(0, \mathbf{g}_{t}^{o}\right)\right)-D_{t}\left(\mathbf{x}_{t}, \mathbf{y}_{t+1} ;\left(0, \mathbf{g}_{t+1}^{o}\right)\right)\right. \\
& -D_{t}\left(\mathbf{x}_{t+1}, \mathbf{y}_{t} ;\left(\mathbf{g}_{t+1}^{i}, 0\right)\right)+D_{t}\left(\mathbf{x}_{t}, \mathbf{y}_{t} ;\left(\mathbf{g}_{t}^{i}, 0\right)\right) \\
& +D_{t+1}\left(\mathbf{x}_{t+1}, \mathbf{y}_{t} ;\left(0, \mathbf{g}_{t}^{o}\right)\right)+D_{t+1}\left(\mathbf{x}_{t+1}, \mathbf{y}_{t+1} ;\left(0, \mathbf{g}_{t+1}^{o}\right)\right) \\
& \left.-D_{t+1}\left(\mathbf{x}_{t+1}, \mathbf{y}_{t+1} ;\left(\mathbf{g}_{t+1}^{i}, 0\right)\right)+D_{t+1}\left(\mathbf{x}_{t}, \mathbf{y}_{t+1} ;\left(\mathbf{g}_{t}^{i}, 0\right)\right)\right\} \\
& -D_{t}\left(\mathbf{x}_{t+1}, \mathbf{y}_{t+1} ;\left(0, \mathbf{g}_{t+1}^{o}\right)\right)-D_{t+1}\left(\mathbf{x}_{t+1}, \mathbf{y}_{t+1} ;\left(\mathbf{g}_{t+1}^{i}, 0\right)\right)+D_{t}\left(\mathbf{x}_{t+1}, \mathbf{y}_{t+1} ;\left(\mathbf{g}_{t+1}^{i}, 0\right)\right)
\end{aligned}
$$

However, this decomposition is incomplete. First, it lacks a scale (in)efficiency change component. Second, there is no reason for TC to be defined as a difference between an output-oriented technical change component and an input-oriented technical change component. Furthermore, TC is only defined with respect to observations in period $t+1$, although there is no clear reason to favor those to observations in period $t$. Finally, the EC component does not capture technical (in)efficiency change.

\section{Appendix B. Decomposition using the input DiRection}

The decomposition using the input direction is:

$$
L H M_{t, t+1}=\Delta T^{i}+\Delta T E I^{i}+\Delta S E C^{i},
$$

representing technical change, technical inefficiency change and scale inefficiency change, respectively.

The technical change component is defined as:

$$
\begin{aligned}
\Delta T^{i} & =\frac{1}{2}\left\{\left[D_{t+1}\left(\mathbf{x}_{t}, \mathbf{y}_{t} ;\left(\mathbf{g}_{t}^{i}, 0\right)\right)-D_{t}\left(\mathbf{x}_{t}, \mathbf{y}_{t} ;\left(\mathbf{g}_{t}^{i}, 0\right)\right)\right]\right. \\
& \left.+\left[D_{t+1}\left(\mathbf{x}_{t+1}, \mathbf{y}_{t+1} ;\left(\mathbf{g}_{t+1}^{i}, 0\right)\right)-D_{t}\left(\mathbf{x}_{t+1}, \mathbf{y}_{t+1} ;\left(\mathbf{g}_{t+1}^{i}, 0\right)\right)\right]\right\},
\end{aligned}
$$

and the same interpretation as before. Technical inefficiency change is:

$$
\Delta T E I^{i}=D_{t}\left(\mathbf{x}_{t}, \mathbf{y}_{t} ;\left(\mathbf{g}_{t}^{i}, 0\right)\right)-D_{t+1}\left(\mathbf{x}_{t+1}, \mathbf{y}_{t+1} ;\left(\mathbf{g}_{t+1}^{i}, 0\right)\right) .
$$


From the residual

$$
\begin{aligned}
L H M_{t, t+1}- & \Delta T^{i}-\Delta T E I^{i}= \\
& \frac{1}{2}\left\{\left[D_{t}\left(\mathbf{x}_{t}, \mathbf{y}_{t} ;\left(0, \mathbf{g}_{t}^{o}\right)\right)-D_{t}\left(\mathbf{x}_{t}, \mathbf{y}_{t+1} ;\left(0, \mathbf{g}_{t+1}^{o}\right)\right)\right]\right. \\
& \left.+\left[D_{t+1}\left(\mathbf{x}_{t+1}, \mathbf{y}_{t} ;\left(0, \mathbf{g}_{t}^{o}\right)\right)-D_{t+1}\left(\mathbf{x}_{t+1}, \mathbf{y}_{t+1} ;\left(0, \mathbf{g}_{t+1}^{o}\right)\right)\right]\right\} \\
- & \frac{1}{2}\left\{\left[D_{t}\left(\mathbf{x}_{t+1}, \mathbf{y}_{t} ;\left(\mathbf{g}_{t+1}^{i}, 0\right)\right)-D_{t}\left(\mathbf{x}_{t+1}, \mathbf{y}_{t+1} ;\left(\mathbf{g}_{t+1}^{i}, 0\right)\right)\right]\right. \\
& \left.+\left[D_{t+1}\left(\mathbf{x}_{t}, \mathbf{y}_{t} ;\left(\mathbf{g}_{t}^{i}, 0\right)\right)-D_{t+1}\left(\mathbf{x}_{t}, \mathbf{y}_{t+1} ;\left(\mathbf{g}_{t}^{i}, 0\right)\right)\right]\right\}
\end{aligned}
$$

we recover the scale inefficiency change component in a similar way as before. Define the projections of $\mathbf{x}_{t}$ and $\mathbf{x}_{t+1}$ on the production frontier at time $t$ :

$$
\begin{aligned}
& \mathbf{x}_{t}^{*}=\mathbf{x}_{t}-D_{t}\left(\mathbf{x}_{t}, \mathbf{y}_{t} ;\left(\mathbf{g}_{t}^{i}, 0\right)\right) \mathbf{g}_{t}^{i} \\
& \mathbf{x}_{t+1}^{* *}=\mathbf{x}_{t+1}-D_{t}\left(\mathbf{x}_{t+1}, \mathbf{y}_{t+1} ;\left(\mathbf{g}_{t+1}^{i}, 0\right)\right) \mathbf{g}_{t+1}^{i},
\end{aligned}
$$

and the projections of $\mathbf{x}_{t}$ and $\mathbf{x}_{t+1}$ on the production frontier at time $t+1$ :

$$
\begin{aligned}
& \mathbf{x}_{t}^{* *}=\mathbf{x}_{t}-D_{t+1}\left(\mathbf{x}_{t}, \mathbf{y}_{t} ;\left(\mathbf{g}_{t}^{i}, 0\right)\right) \mathbf{g}_{t}^{i} \\
& \mathbf{x}_{t+1}^{*}=\mathbf{x}_{t+1}-D_{t+1}\left(\mathbf{x}_{t+1}, \mathbf{y}_{t+1} ;\left(\mathbf{g}_{t+1}^{i}, 0\right)\right) \mathbf{g}_{t+1}^{i} .
\end{aligned}
$$

Respectively adding and subtracting $D_{t}\left(\mathbf{x}_{t}, \mathbf{y}_{t} ;\left(\mathbf{g}_{t}^{i}, 0\right)\right)$ and $D_{t+1}\left(\mathbf{x}_{t+1}, \mathbf{y}_{t+1} ;\left(\mathbf{g}_{t+1}^{i}, 0\right)\right)$ to and from (B.4), and using the translation property of the directional distance function and the definitions of the projections above, we find the scale inefficiency change component:

$$
\begin{aligned}
\Delta S E C^{i} & =\frac{1}{2}\left\{\left[D_{t}\left(\mathbf{x}_{t}, \mathbf{y}_{t} ;\left(0, \mathbf{g}_{t}^{o}\right)\right)-D_{t}\left(\mathbf{x}_{t}, \mathbf{y}_{t+1} ;\left(0, \mathbf{g}_{t+1}^{o}\right)\right)\right]\right. \\
& -\left[D_{t}\left(\mathbf{x}_{t+1}^{* *}, \mathbf{y}_{t} ;\left(\mathbf{g}_{t+1}^{i}, 0\right)\right)-D_{t}\left(\mathbf{x}_{t}^{*}, \mathbf{y}_{t} ;\left(\mathbf{g}_{t}^{i}, 0\right)\right)\right] \\
& +\left[D_{t+1}\left(\mathbf{x}_{t+1}, \mathbf{y}_{t} ;\left(0, \mathbf{g}_{t}^{o}\right)\right)-D_{t+1}\left(\mathbf{x}_{t+1}, \mathbf{y}_{t+1} ;\left(0, \mathbf{g}_{t+1}^{o}\right)\right)\right] \\
& \left.-\left[D_{t+1}\left(\mathbf{x}_{t+1}^{*}, \mathbf{y}_{t+1} ;\left(\mathbf{g}_{t+1}^{i}, 0\right)\right)-D_{t+1}\left(\mathbf{x}_{t}^{* *}, \mathbf{y}_{t+1} ;\left(\mathbf{g}_{t}^{i}, 0\right)\right)\right]\right\} \\
& \equiv \frac{1}{2}\left\{\Delta S E C_{t}^{i}+\Delta S E C_{t+1}^{i}\right\} .
\end{aligned}
$$

\section{Appendix C. State-Level TFP figures}

This appendix includes the LHM TFP indicator and its components per agricultural region. Each figure is constructed by averaging over all states in that particular agricultural region in every year.

\section{C.1. Convex technology.}




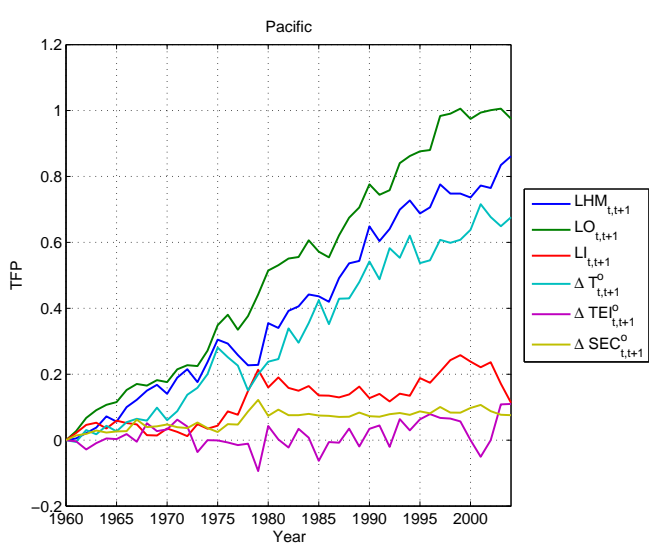

(A) Pacific

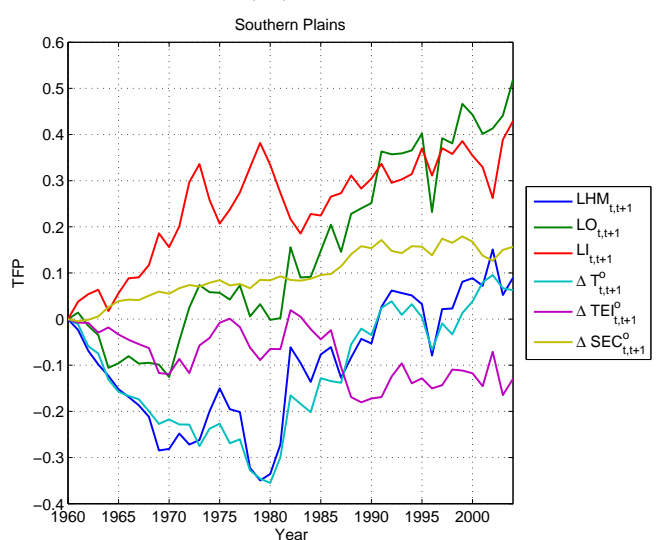

(D) Southern Plains

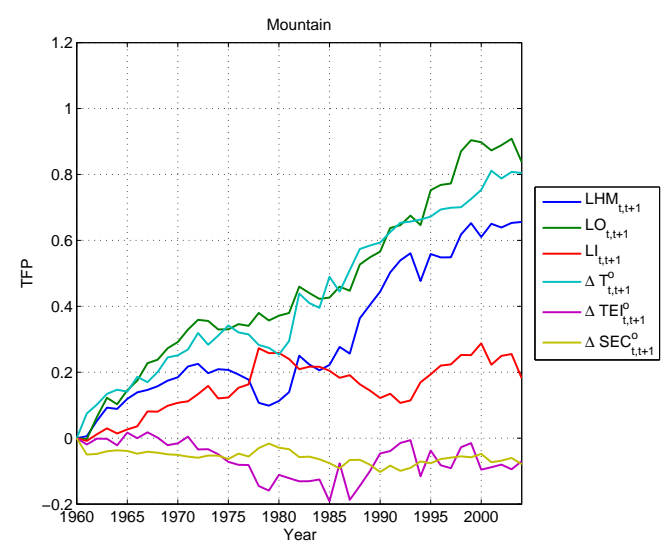

(B) Mountain

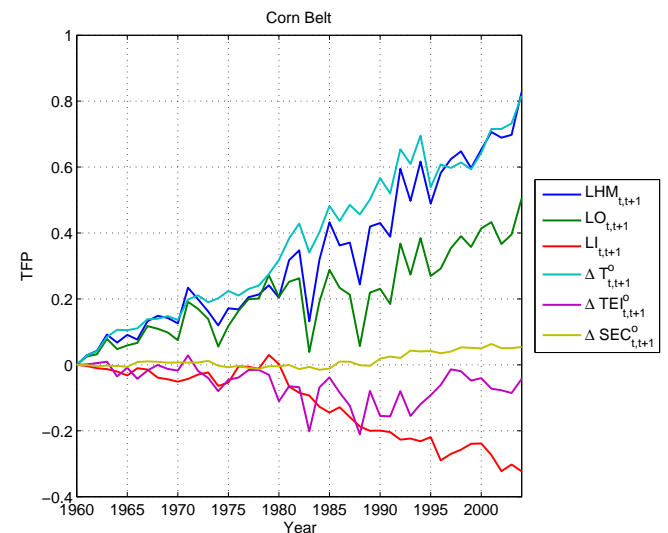

(E) Corn Belt

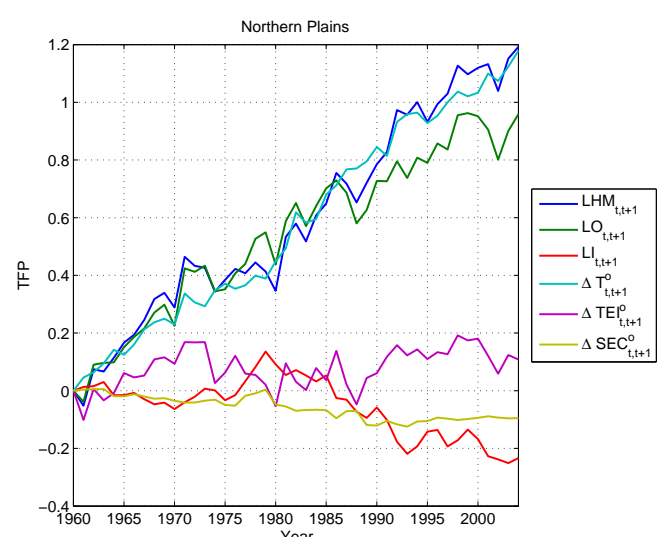

(C) Northern Plains

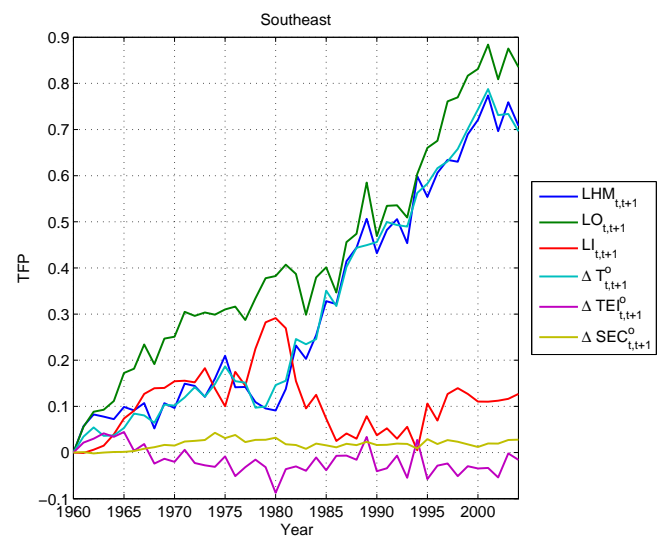

(F) Southeast

Figure C.1. Cumulative LHM TFP indicator and its components per agricultural region under a convex technology 


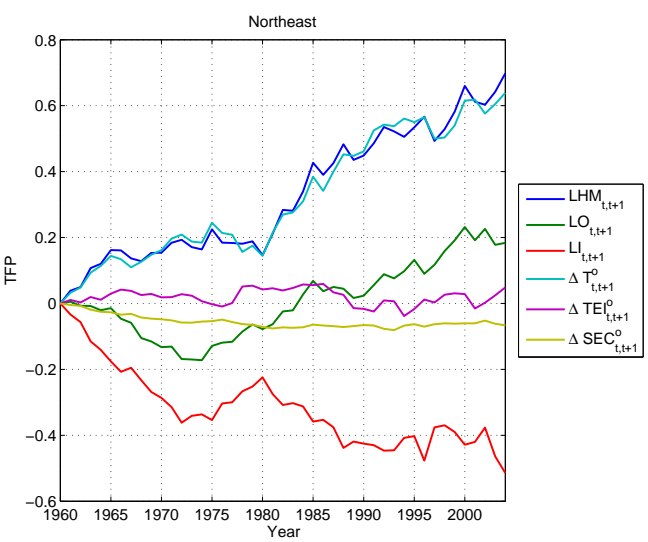

(G) Northeast

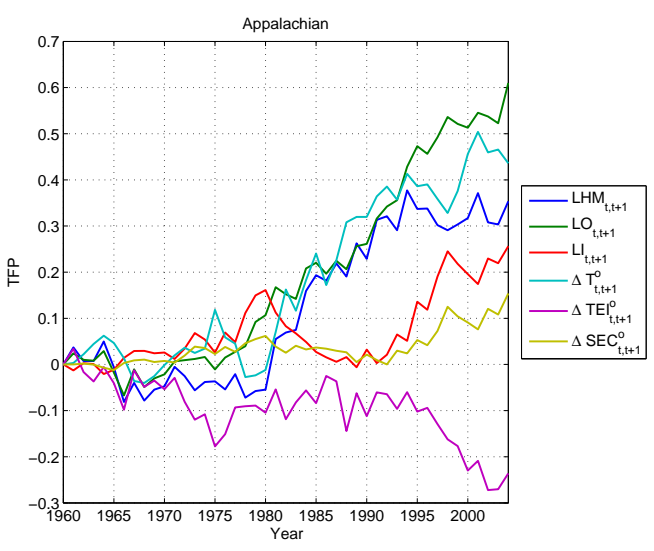

(I) Appalachian

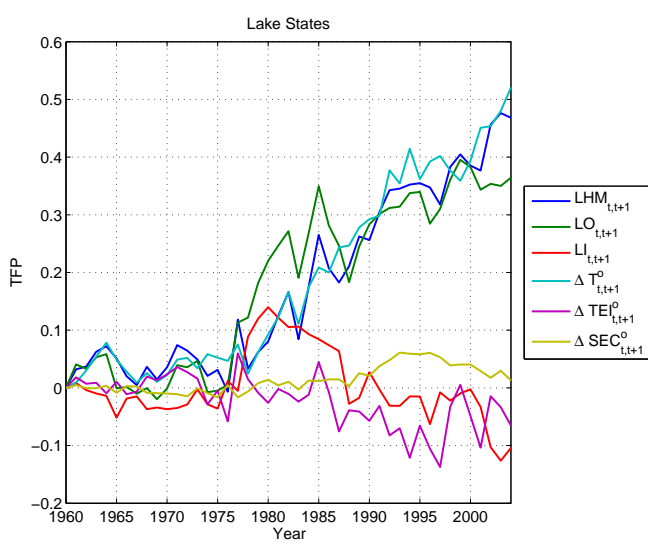

(H) Lake States

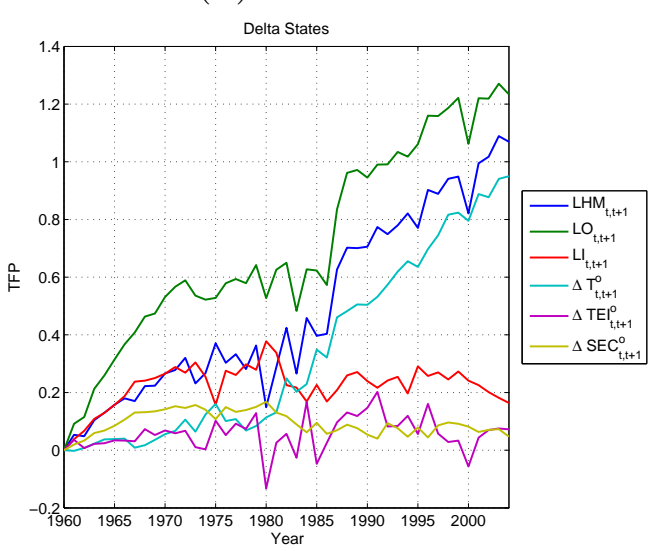

(J) Delta States

Figure C.1. Cumulative LHM TFP indicator and its components per agricultural region under a convex technology

\section{C.2. Non-convex technology.}




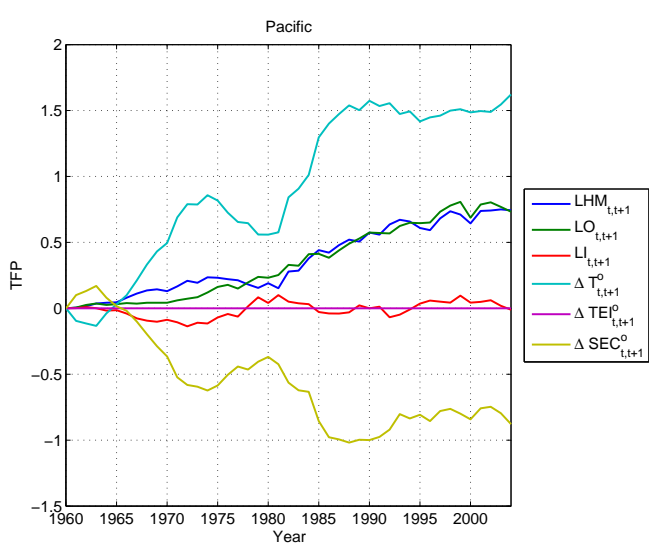

(A) Pacific

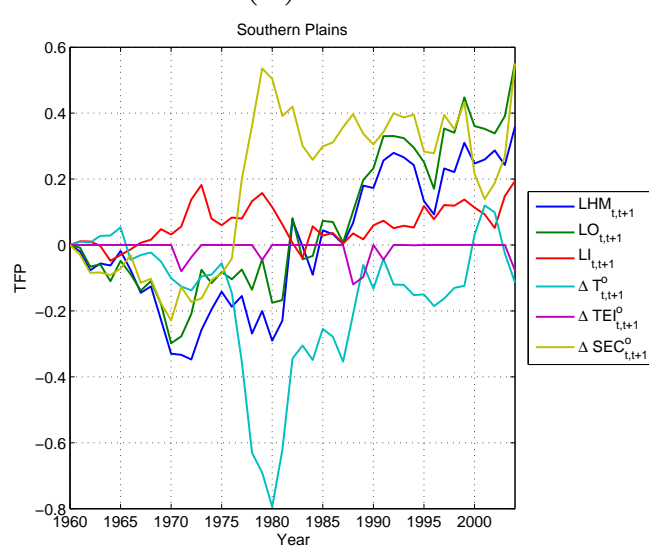

(D) Southern Plains

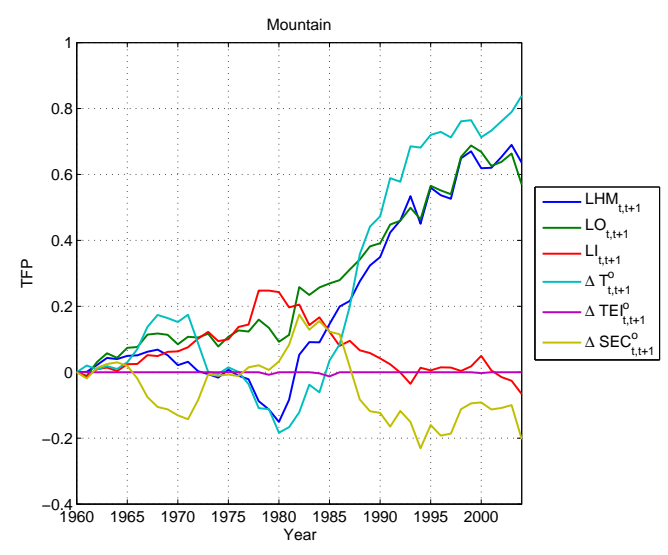

(B) Mountain

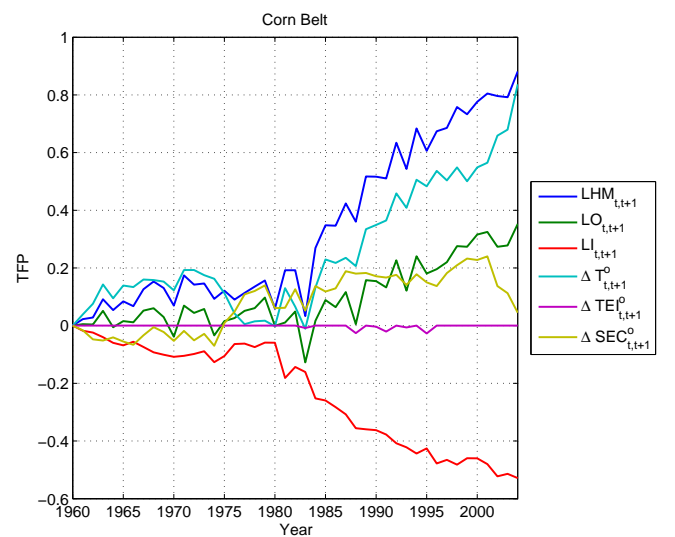

(E) Corn Belt

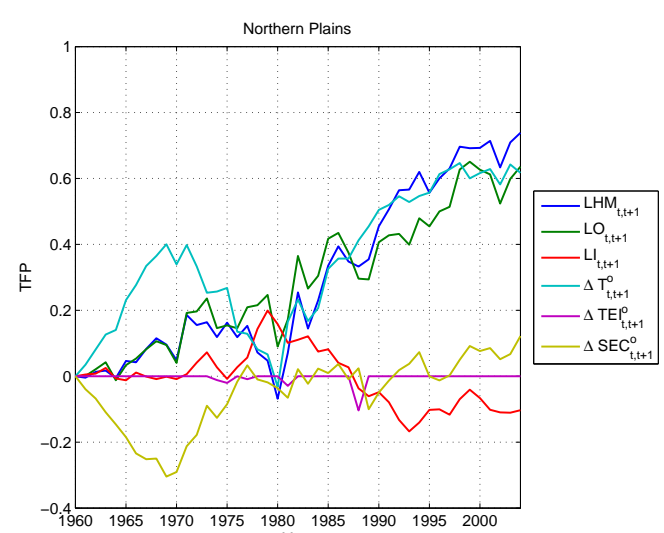

(C) Northern Plains

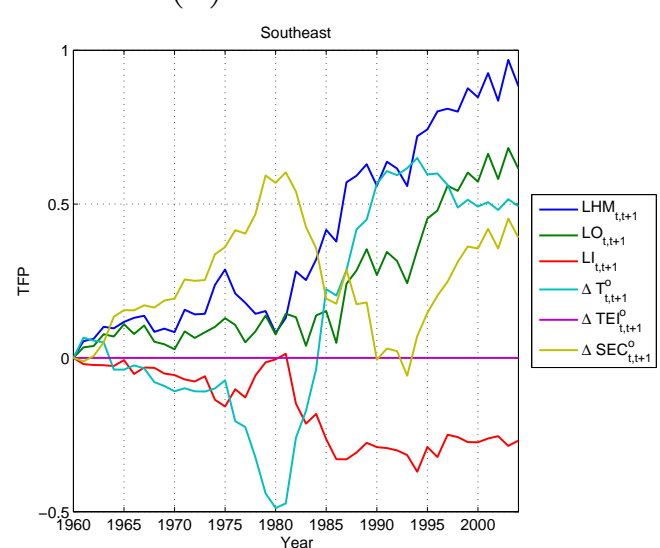

(F) Southeast

Figure C.2. Cumulative LHM TFP indicator and its components per agricultural region under a non-convex technology 


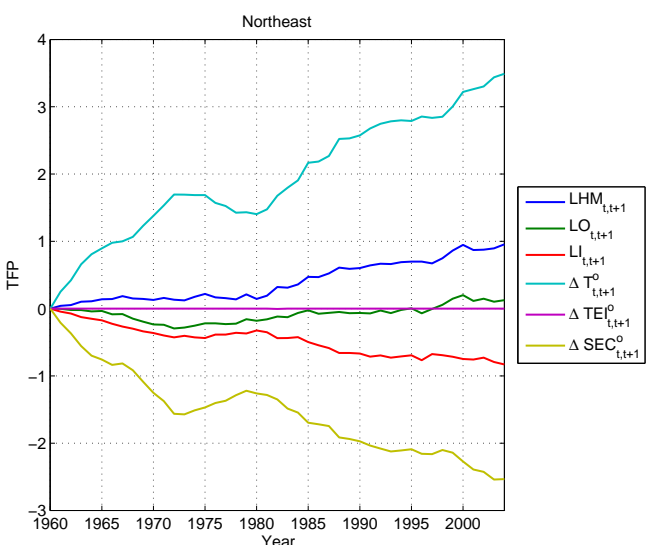

(G) Northeast

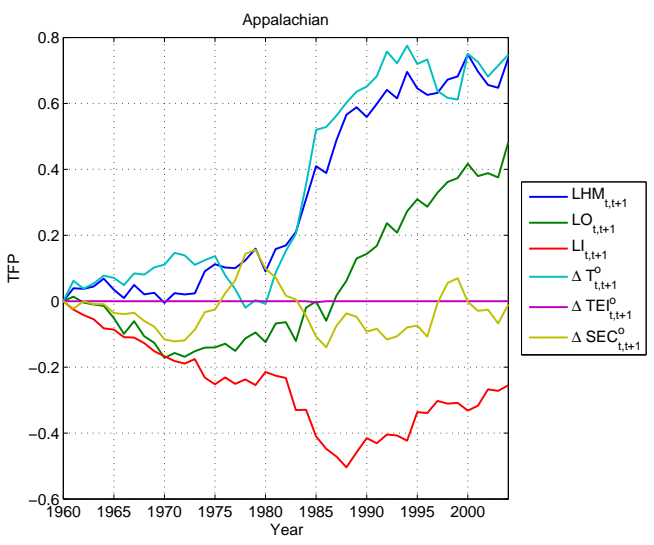

(I) Appalachian

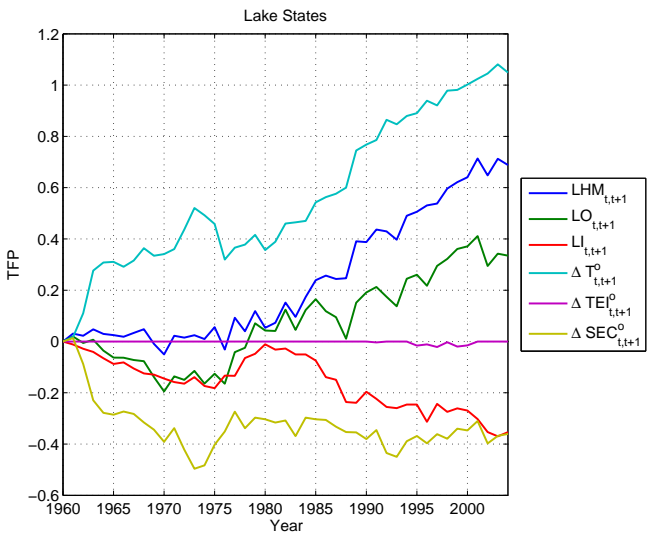

(н) Lake States

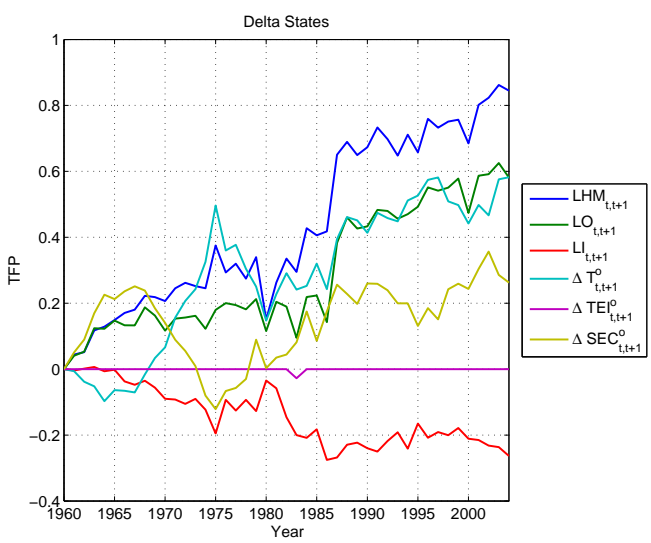

(J) Delta States

Figure C.2. Cumulative LHM TFP indicator and its components per agricultural region under a non-convex technology 